\title{
Quantitative heterodonty in Crocodylia: assessing size and shape across modern and extinct taxa
}

\author{
Domenic C D'Amore ${ }^{\text {Corresp., }}{ }^{1}$ ， Megan Harmon ${ }^{1}$, Stephanie K Drumheller ${ }^{2}$, Jason J Testin ${ }^{3}$ \\ 1 Department of Natural Sciences, Daemen College, Amherst, NY, United States \\ 2 Department of Earth and Planetary Sciences, University of Tennessee - Knoxville, Knoxville, Tennessee, United States \\ 3 Department of Physical Science, Physics and Pre-Engineering, lowa Western Community College, Council Bluffs, IA, United States \\ Corresponding Author: Domenic C D'Amore \\ Email address: ddamore@daemen.edu
}

Heterodonty in Crocodylia and closely related taxa has not been defined quantitatively, as the teeth rarely have been measured. This has resulted in a range of qualitative descriptors, with little consensus on the condition of dental morphology in the clade. The purpose of this study is to present a method for the quantification of both size- and shapeheterodonty in members of Crocodylia. Data were collected from dry skeletal and fossil specimens of 34 crown crocodylians and one crocodyliform, resulting in 21 species total. Digital photographs were taken of each tooth and the skull, and the margins of both were converted into landmarks and semilandmarks. We expressed heterodonty through Foote's morphological disparity, and a principal components analysis quantified shape variance. All specimens sampled were heterodont to varying degrees, with the majority of the shape variance represented by a 'caniniform' to 'molariform' transition. Heterodonty varied significantly between positions; size undulated whereas shape was significantly linear from mesial to distal. Size and shape appeared to be primarily decoupled. Skull shape correlated significantly with tooth shape. High size-heterodonty often correlated with very large caniniform teeth, reflecting a prioritization of securing prey. Large, highly molariform, distal teeth may be a consequence of high-frequency durophagy combined with prey size. The slender-snouted skull shape correlated with a caniniform arcade with low heterodonty. This was reminiscent of other underwater-feeding tetrapods, as they often focus on small prey that requires minimal processing. Several extinct taxa were very molariform, which was associated with low heterodonty. The terrestrial peirosaurid shared similarities with large modern crocodylian taxa, but may have processed prey differently. Disparity measures can be inflated or deflated if certain teeth are absent from the tooth row, and regression analysis may not best apply to strongly slender-snouted taxa. Nevertheless, when these methods are used in tandem they can give a complete picture of crocodylian heterodonty. Future researchers may apply our proposed method to most crocodylian 
specimens with an intact enough tooth row regardless of age, species, or rearing conditions, as this will add rigor to many life history studies of the clade. 
1 TITLE: Quantitative heterodonty in Crocodylia: assessing size and shape across modern and

2 extinct taxa.

3 AUTHORS: Domenic C. D’Amore*1, Megan Harmon¹, Stephanie K. Drumheller², Jason J. Testin ${ }^{3}$

4 1. Department of Natural Sciences, Daemen College, 4380 Main Street, Amherst, New $5 \quad$ York 14226 United States of America

62 Department of Earth and Planetary Sciences, University of Tennessee, 1621 Cumberland Avenue, 602 Strong Hall, Knoxville, Tennessee 37996 United States of America

3. Department of Physical Science, Physics and Pre-Engineering, lowa Western Community College, 2700 College Road, Council Bluffs, lowa, 51503 United States of America

*Corresponding Author: Domenic C. D’Amore, ddamore@daemen.edu 


\section{ABSTRACT}

Heterodonty in Crocodylia and closely related taxa has not been defined quantitatively, as the teeth rarely have been measured. This has resulted in a range of qualitative descriptors, with little consensus on the condition of dental morphology in the clade. The purpose of this study is to present a method for the quantification of both size- and shape-heterodonty in members of Crocodylia. Data were collected from dry skeletal and fossil specimens of 34 crown crocodylians and one crocodyliform, resulting in 21 species total. Digital photographs were taken of each tooth and the skull, and the margins of both were converted into landmarks and semilandmarks. We expressed heterodonty through Foote's morphological disparity, and a principal components analysis quantified shape variance. All specimens sampled were heterodont to varying degrees, with the majority of the shape variance represented by a 'caniniform' to 'molariform' transition. Heterodonty varied significantly between positions; size undulated whereas shape was significantly linear from mesial to distal. Size and shape appeared to be primarily decoupled. Skull shape correlated significantly with tooth shape. High size-heterodonty often correlated with very large caniniform teeth, reflecting a prioritization of securing prey. Large, highly molariform, distal teeth may be a consequence of high-frequency durophagy combined with prey size. The slender-snouted skull shape correlated with a caniniform arcade with low heterodonty. This was reminiscent of other underwater-feeding tetrapods, as they often focus on small prey that requires minimal processing. Several extinct taxa were very molariform, which was associated with low heterodonty. The terrestrial peirosaurid shared similarities with large modern crocodylian taxa, but may have processed prey differently. Disparity measures can be inflated or deflated if certain teeth are absent from 
the tooth row, and regression analysis may not best apply to strongly slender-snouted taxa. Nevertheless, when these methods are used in tandem they can give a complete picture of crocodylian heterodonty. Future researchers may apply our proposed method to most crocodylian specimens with an intact enough tooth row regardless of age, species, or rearing conditions, as this will add rigor to many life history studies of the clade.

\section{INTRODUCTION}

What constitutes heterodonty in vertebrates is often difficult to delineate, with different qualitative definitions in place depending on the clade being studied (Shimada, 2001). Kieser et al. (1993, p.195) referred to the definition of heterodonty as "a bone of contention," and since then the issue has not been fully resolved. Arguably, this lack of clarity is most pronounced within members of Crocodylia. Researchers have often referred to crocodylians as homodont (Langston, 1973; Osborn, 1998; Larsson \& Sidor, 1999; Zahradnicek et al., 2014). Peyer (1968 p.17) defined the term as lacking the discrete dental categories seen in mammals (incisors, canines, premolars, molars), even though he admitted "a sharp distinction between homodont and heterodont is not possible." Ferguson (1981) referred to Alligator mississippiensis as "pseudoheterodont," because it showed a gradual, as opposed to punctuated, change in tooth shape along the tooth row (see also Grigg and Gans, 1993; Hendrickx, Mateus, \& Araújo, 2015a). Size variability along the tooth row has motivated the term "heterometric homodonty" for Crocodylus niloticus (Fruchard, 2012). Others have applied anisodonty to the clade, which is an apparent change in tooth size but not shape (Vullo et al., 2016). Certain fossil crocodylians, 
56

57

often interpreted as herbivores or omnivores, exhibit multi-cusped and/or grinding teeth, and are specifically called "heterodont" crocodyliforms by researchers (e.g. Martin, 2007; Ősi, Clark, \& Weishampel, 2007; Novas et al., 2009; Ősi, 2014). Lastly, some researchers have argued certain modern crocodylians are actually heterodont, and claim dental categories do in fact exist (Aoki, 1989; Kieser et al., 1993).

Semantics aside, one reason for the lack of resolution concerning crocodylian heterodonty is that their teeth rarely have been measured. Few studies have performed quantitative shape analyses of crocodylian teeth. Of these, linear-distance measures have been used for fossil identification (Frey \& Monninger, 2010), replacement rates (Bennett, 2012), and biomechanical analyses (Monfroy, 2017). Aside from a study evaluating two fossil notosuchians (Lecuona \& Pol, 2008), and a preliminary geometric morphometric investigation of Crocodylus niloticus (Farrugia, Polly, \& Njau, 2016), no studies have quantitatively investigated heterodonty either within or between species. Typically, crocodylian dentition is described qualitatively, with the goal of characterization for phylogenetic analysis, or paleoecological inference (e.g.

Schwarz-Wings, Rees, \& Lindgren, 2009; Young et al., 2012; Salas-Gismondi et al., 2015; Adams, Noto, \& Drumheller, 2017). Qualitative descriptors of crocodylian tooth morphology are numerous, and include terms such as "blunt," "bulbous," "broadened," "button-shaped," "conical," "globular," "fang," "kidney-shaped," “lanceolate," “needle-like," "procumbent," "pseudocanine," "robust," "short," "slender," "spike-like," and "thick" (e.g. Brazaitis, 1973; Groombridge, 1982; Aoki, 1989; Brochu, 1999; Erickson, Lappin, \& Vliet, 2003; Ősi, Clark, \& Weishampel, 2007; Schwarz-Wings, Rees, \& Lindgren, 2009; Fruchard, 2012; Gignac \& Erickson, 2014; Salas-Gismondi et al., 2015; Berkovitz and Shellis, 2017). There is clearly a gap in our 
knowledge concerning the nature of dental morphology in this clade, and closing this gap may be crucial for a more complete understanding of performance, behavior, and trophic ecology within Crocodylia, as well as more distantly related, crocodylian-line archosaurs.

The lack of quantitative studies on heterodonty in crocodylians and closely related taxa is not due to a lack of applicable methodology, as there has been a burst of morphometric research in non-mammalian teeth in the past decade. Dinosaur teeth have probably received the most attention, with multiple studies using linear-distance measures for the identification of loose fossil crowns or to infer functional paleoecology (D'Amore, 2009; Larson \& Currie, 2013; Buckley and Currie, 2014; Hendrickx and Mateus, 2014; Torices, Reichel, \& Currie, 2014; Hendrickx, Mateus, \& Araújo, 2015b, Gerke and Wings, 2016; Larson, Brown, \& Evans, 2016). Similar measurements have been taken from a number of extinct marine reptiles (Foffa et al., 2018). Extant reptiles have been investigated quantitatively as well, including colubrid snakes (Britt, Clark, \& Bennett, 2009; Juarez \& D’Amore, 2018) and varanid lizards (D'Amore, 2015). Prior to this, sharks were studied heavily (Shimada, 2002b, 2004; Shimada and Seigel, 2005; Ciampaglio, Wray, \& Corliss, 2005). These morphometric analyses have shed light on the nature of heterodonty, dental allometry, and ecomorphology in these vertebrates, and similar methods may be applied to Crocodylia to clarify the state of heterodonty in this taxon. shape-heterodonty in members of Crocodylia. Data were collected from a multispecific sample of both extant and extinct specimens housed in museum collections, and their tooth morphology was assessed through two-dimensional geometric morphometric methods. In 
99

100

101

102

103

104

105

106

107

108

109

110

111

112

113

114

115

116

117

118

addition to this major goal, we also 1) outline and describe dental morphology within the specimens sampled; 2) report any morphological consistencies found within the members of our sample; and 3) present the advantages, limitations, and potential future uses of the method. Our intention is to put forward a method for assessing heterodonty that may be applicable to most crocodylian specimens, and may allow for direct comparisons between crocodylians and a variety of other terrestrial and aquatic tetrapods.

\section{MATERIALS AND METHODS}

\section{Institutional abbreviations}

American Museum of Natural History, New York, NY (AMNH); Royal Ontario Museum, Toronto, ON (ROM); University of California Museum of Paleontology, Berkeley, CA (UCMP)

\section{Nomenclature}

Crocodylian teeth have very few discrete homologous anatomical loci, but, because they exhibit thecodont dentition (sensu Edmund, 1962, 1969), we defined them as having a crown with an apex, a neck, and a root within an alveolus. Nomenclature for tooth morphology used here was proposed by Smith \& Dodson (2003; Figure 1A-B): mesial, towards the point where the premaxillae meet at the midline, or towards the mandibular symphysis; distal, away from the medial premaxillae or the mandibular symphysis; lingual, towards the tongue; labial, towards the "lips"; basal, towards the base of the tooth or alveolus; apical, away from the alveolus or towards the apex. Crocodylians are known for a condition where a large tooth may be surrounded by much smaller ones. This large tooth is typically referred to as a procumbent 
119 tooth (Gignac \& Erickson, 2014) or a pseudocanine (Brochu, 1999), but we simply refer to it as

120 'enlarged.'

121 Tooth position was indicated by either the presence of a tooth or an empty alveolus in

122 the host bone (Figure 1A). Teeth were lettered based on the host bone (premaxilla $=\mathrm{P}$, maxilla

$123=\mathrm{M}$, dentary = D), and numbered in ascending order from mesial to distal positions (the mesial-

124 most dentary tooth was D1, followed by D2, D3, etc.). For consistency, all specimens were

125

assumed to have five premaxillary positions (P1-P5) (Berkovitz \& Shellis, 2017). Members of

Paleosuchus and Osteolaemus have only four premaxillary teeth during early stages of

127

ontogeny (Brochu and Storrs, 2012; Narvaez et al., 2015), and an alveolus may atrophy in

128

certain species (usually P2) as they grow (Webb \& Messel, 1978; Brown et al., 2015; DC

D’Amore, personal observation). If only four premaxillary positions were present, position P2

was assumed absent, and skipped over during numbering. In one case, a specimen had six

premaxillary teeth (Alligator mississippiensis, ROM 4408). This tooth position (P6) was omitted

for consistency. Our Alligator prenasalis specimen (ROM 1375) had its distal-most cranial

positions obscured by poor preservation and matrix. We therefore based its maxillary tooth

count on previous osteological accounts (a total of 15 maxillary teeth based on Harvard

Museum of Comparative Zoology specimen \#1015, Mook, 1932).

\section{Specimens}

137 Data were collected from 20 species of crown crocodylians, and one species of peirosaurid

138 crocodyliform (Supplemental Information Table S1). We included the later as it was readily

139 available with excellent tooth preservation, and allowed us to consider if characteristics 
140 indicative of crocodylian heterodonty may be found in species outside the crown clade. The end

141 result was 27 extant and eight extinct specimens, from which we measured 1,263 teeth in total.

142 Although Caiman crocodilus is extant, a fossil specimen (UCMP 42844) was also included.

143 Although we did not use any distinct criteria to distinguish juveniles from adults, larger

144 specimens were selected when possible. We chose specimens with the most complete tooth

145 rows in the collections, in that they had the most tooth positions represented by measurable

146 teeth on at least one side of the mouth. Because of normal tooth replacement, post-mortem

147 damage, and/or poor preservation, the percentage of tooth positions represented by

148 measurable teeth was highly variable (Supplemental Information Table S2). Modern specimens

149 had tooth rows with $42-100 \%$ of their tooth positions represented, and fossil tooth rows ranged

$15030-78 \%$. Certain fossil specimens only had cranial (Alligator prenasalis ROM 1375,

151 Borealosuchus sternbergii UCMP 126099, "Crocodylus" affinis UCMP 131090, Hamadasuchus

152 rebouli ROM 52620, Leidyosuchus canadensis ROM 1903) or dentary (Borealosuchus sternbergii

153 UCMP 131769) material to sample. This variability allowed us to consider in what way the

154 degree of incompleteness along the tooth row may affect the proposed method, as incomplete

155 tooth rows may be common in collections.

\section{Tooth data collection}

157 Methods were similar to those proposed by D'Amore (2015). We photographed each tooth

158 using either an Olympus Stylus or a Canon Rebel T3 EOS camera with a non-zoom lens. Skulls

159 were positioned on a flat surface with a dark background such as a tabletop or camera stand,

160 and held stationary by an available prop such as a box or sandbag if necessary. A scale was 
161 positioned at the same distance from the camera as the tooth. The camera was either mounted

162 on a camera stand, or was held stationary by a researcher (for larger specimens). Digital

163 photographs were taken from the labial perspective (Figure 1B). For each tooth, we positioned

164 the specimen so the camera lens was parallel to the host bone adjacent to the tooth. This

165 resulted in both carinae being visible in the shot (if present). We simultaneously positioned the

166 lens parallel to the apical-basal long axis, determined qualitatively as when the tooth looked its

167 tallest to the photographer regardless of any labio-lingual curvature. Each tooth was

168 photographed separately, and teeth from both sides were photographed if available. Only fully

169 erupted teeth with the neck visible were included (Figure 1B). Tooth quality was variable in

170 extant specimens. Teeth with slightly worn apices were included. As the outline of the tooth

171 margin was our basis of measurement, we omitted any teeth with large wear facets or chips

172 that largely interrupted this margin. Cracks down the long axis of the teeth were common, and

173 were omitted if the crack distorted the shape of the tooth or resulted in a space where light

174 could be seen from the other side.

We used a sliding semilandmark analysis (Bookstein, 1997; Sheets, Kim, \& Mitchell 2004;

Zelditch et al., 2004; Mitteroecker et al., 2013) to derive shape measurements from each

traced using the curve drawing tool (Rohlf, 2010) (Figure 1B). Because the enamel margin was

not always clear, each tooth was traced from apex to the point where the tooth ceased to taper 
183

184

185

186

187

188

189

190

191

192

193

194

195

196

197

198

199

200

201

202

203

semilandmarks (Figure 1B). This number of coordinates has been used in previous studies of both dinosaur (Smith, Vann, \& Dodson, 2005) and monitor lizard (D'Amore, 2015) dentition, as well as claw morphology (Tinius and Russel, 2016; D'Amore et al., 2018), in which it has been shown to accurately represent the totality of two-dimensional shape (Tinius and Russel, 2016).

We calculated centroid size (CS), and performed a generalized least squares Procrustes (GLSP) superimposition while sliding the semilandmarks to minimize the total bending energy (Perez, Bernal, \& Gonzalez, 2006; Gunz \& Mitteroecker, 2013), using the program TpsRelw 1.53 (Rohlf, 2013).

\section{Skull data collection}

The shape of the skull, and particularly the rostrum, has long been considered both an important phylogenetic and ecomorphological feature in crocodylians (Busbey, 1995; Daniel \& McHenry, 2001; Brochu, 2001; Sadleir \& Makovicky, 2008; Salas-Gismondi et al., 2016;

Drumheller, Wilberg, \& Sadlier, 2016; Wilberg, 2017). We attempted to determine if there was a correlation between tooth morphology and head shape, as these traits may be linked. All specimens' skulls were photographed from the dorsal perspective using the same cameras as above (Figure 1C). Each skull was positioned so the palate was parallel with the tabletop, and the camera was positioned with a camera stand and leveled. A scale was included. We derived skull shape data using a modified version of our technique for tooth outlines. Using TpsDig again, we traced the skull margin from the rostral-most point of contact between the premaxillae to the caudal-most quadratojugal along the margin on each side (Figure $1 \mathrm{C}$ ). We chose this margin because it outlined the shape of the head as close to as it would have 
204 appeared in life as possible, but avoided internal structures such as the jaw articulations or 205 occipital condyles. Each margin was broken into 50 equidistant coordinates, and the rostral206 most coordinates were combined. This resulted in three landmarks (two at the quadratojugals 207 and one at the premaxillary junction) and 97 semilandmarks (Figure 1C). These also underwent 208 a GLSP superimposition and the semilandmarks were slid to minimize the total bending energy 209 using TpsRelw 1.53. In specimens with damaged or missing bones on one side, bilateral symmetry was assumed and the coordinates on the intact side were mirrored. This was achieved by placing another landmark along the mid-sagittal plane at the caudal-most point available. This landmark and the one at the premaxillary junction resulted in a plane that the landmarks were mirrored against.

few were available for all specimens. Commonly used metrics such as snout-vent length and mass were not recorded for most dry skeletons prior to cataloging, and many specimens used as a body size metric (see Fukuda et al. 2013 for potential influences on this measurement). We derived skull length from the same landmarks outlining the skull above; it was the linear distance from the rostral-most landmark to the posterior-most landmarks along the mid-sagittal plane (Figure 1C). (Note: Borealosuchus sternbergii UCMP 131769 and

222 Crocodylus niloticus AMNH 142494 did not have intact skulls, and were therefore omitted from 223 all analyses involving skull data.)

\section{Statistical approaches}


225 All analyses were conducted in MorphoJ v. 106d (Klingenberg 2011), SPSS Version 19.0 [IBM

226 Corp, Armonk, NY], and PAST (Hammer, Harper, \& Ryan, 2001). If both left and right teeth were

227 available at a given position, we averaged them. For size, CS values were simply averaged

228 together. For shape, each $x-y$ coordinate of the GLSP superimposed landmarks and

229 semilandmarks was averaged with its counterpart for both teeth. To ensure that the left and

230 right sides were not significantly different, we ran a 10,000 permutations test on the Procrustes

231 distances between left and right teeth at positions that had both. This test failed to reject the

232 null hypothesis of bilateral symmetry $(p=0.6785)$. If only one tooth was available for a given

233 position, that tooth alone represented said position.

We tested the null hypothesis that there was no statistical difference between tooth

rows in our sample. We ran a 10,000 permutations test on the Procrustes distance between

cranial (premaxilla and maxilla) and dentary teeth for those that had both.

(Erickson et al., 2004; Drumheller, Wilberg, \& Sadleir, 2016), and how this influences tooth

shape in crocodylians has yet to be determined. All the modern specimens sampled in this

latter category indicated the host museum did not know the living conditions of the specimen

while alive, and could mean (but does not guarantee) that the specimen was captive raised. To 
245

246

excluded Gavialis gangeticus, Mecistops cataphractus, and Tomistoma schlegelii, as they represent an extreme cranial condition and only one individual of each species was available.

morphological disparity $\left[M D=\left(\sum_{i=1}^{m} D_{i}^{2}\right) /(m-1)\right]$ (Foote, 1993; Zelditch, Sheets, \& Fink, 2003; Sheets \& Zelditch, 2013). Disparity (MD) was the sum of the differences of the values of a given tooth (i) from the mean for all teeth from that single specimen ( $D i$, also known as the grand mean) squared, with the number of tooth positions $(m)$ factored in. We calculated disparity for all occupied tooth positions for each specimen. For size-heterodonty, Di was simply the difference in CS of a tooth from the mean of the specimen (Zelditch et al., 2004). For shapeheterodonty Di was the Procrustes distance between the tooth and the mean, and was calculated using DisparityBox7 (Sheets, 2012). Heterodonty then was regressed with reduced major axis against skull length to determine if there was a significant allometric change in the clade. To test if the more incomplete tooth rows were strongly affecting heterodonty, we ran both regressions a second time, yet only included specimens that had no less than $70 \%$ of their tooth rows represented by measurable teeth. If the regression statistics were similar to when all specimens were included, this would suggest incompleteness had a minor effect on our results.

$$
\text { two-block partial least squares (PLS) analysis in MorphoJ. Skull shape represented one block, }
$$
and average tooth shape represented the other. Average tooth shape was constructed by averaging the corresponding GLSP superimposed landmarks and semilandmarks of every tooth 
266 from an individual. The scores for the first PLS of each shape block were plotted against one

267 another and regressed with a reduced major axis. Visualization of variation along each PLS axis

268 was depicted through vector diagrams.

To determine if size and shape were coupled, regression scores of full shape data were generated by MorphoJ (as described in Drake and Klingenberg, 2008) and regressed against CS using a reduced major axis. Significance and a high goodness of fit would be indicative of strong coupling between size and shape. A principal component analysis (PCA) was then conducted to visualize the degree of shape variance within all cranial and dentary teeth. PC scores were represented in bivariate plots, and the shape variation of each PC axis was visualized using vector diagrams.

As heterodonty is defined here as variability along the tooth row, we attempted to evaluate the nature of this variability between tooth positions. We used an analysis of variance (ANOVA) to determine if the teeth differed significantly in CS between positions for all specimens sampled. This size metric had unequal variances according to Levene's test, so we specifically ran a Welch's ANOVA. As shape is inherently a multivariate measure, we ran a multivariate analysis of variance (MANOVA) comparing shape between positions. As some specimens had fewer tooth positions than others, the number of teeth occupying the distalmost positions ended up being low. These positions were excluded from the statistical tests, resulting in the only positions considered having at least 7 teeth. To visually represent variability by position, we plotted size and shape against tooth position in a series of box plots. For size, CS was normalized by dividing it by skull length (so as to not obscure the degree of 
287 variability in smaller specimens), and then was plotted against tooth position. For shape, PC

288 scores of biologically relevant PCs were plotted against tooth position in a similar fashion.

Preliminary quantitative work has suggested a linear transition in tooth shape along the arcade from mesial to distal (Farrugia, Polly, \& Njau, 2016). We test this by regressing shape data against tooth position using ordinary least squares regressions for each individual. To standardize these regressions, we normalized tooth position into a proportion. We numbered the positions along the tooth row starting with 1 at the mesial-most position, divided each by the total number of positions along the arcade, and then subtracted 0.5 (this subtraction placed the $y$-intercept halfway along the arcade without affecting any ensuing statistics). PCs for each tooth were then regressed against this, and regression statistics were collected. Several factors may be implied by a significantly linear crocodylian tooth row. Slope may be linked to heterodonty, as a steeper slope would imply more shape change along the PC1 scores at the $y$ axis and consequently greater shape-heterodonty. The $y$-intercept represented the shape value at the median position, as the intercept was located half-way along the tooth row. This allowed

for direct shape comparison between all taxa regardless of whether or not the tooth was actually present at said position. To visualize these coefficients, we plotted both slope and yintercept for each regression in scatterplots for both the cranium and the dentary.

\section{Results:}

\section{Shape variability in the sample}

No statistically significant difference was found between cranial and dentary tooth rows $(p=0.2455)$ or wild caught versus 'no data' modern specimens ( $p=0.4229)$, failing to reject the 
308

309

310

311

312

313

null hypothesis under both circumstances. When regression scores were plotted against CS, the regression had a goodness of fit accounting for less than $10 \%$ of the variance $(y=0.313 x-$ $\left.0.981 ; r^{2}=0.09 ; p<0.0001 ; 95 \%=0.296,0.328\right)$. Most of the shape variance in Crocodylia was along a single PC axis. PC1 accounted for over $92.11 \%$ of the variance (Supplemental information Table S3). The shape changes towards negative PC1 scores include apical-basal elongation, narrowing at the base, and a gentle concavity on the distal margin (Figure 2A). For simplicity, we will refer to this extreme as 'caniniform' (Erickson et al., 2012; 2014; Gignac \& Erickson, 2014). Positive shape changes depicted an apical-basal shortening and mesial-distal broadening, and we will refer to the extreme as 'molariform' (Erickson et al., 2012; 2014; Gignac \& Erickson, 2014). We describe PC2 (3.22\% of the variance) as the orientation of the tooth, or how much it 'leans' (Figure 2A). Positive values indicate the apex leaning in the mesial direction, and negative values indicate a lean in the distal direction. Note that this is not a measure of curvature, as neither margin changes its concavity or convexity. We do not consider any other PCs, as the amount of variance represented by them is very low (Supplemental Information Table S3).

Figure 2B illustrates the morphospace produced by PC1 and PC2 scores. At the superfamily level, there was a large amount of overlap between alligatoroids and crocodyloids. Most specimens had teeth ranging a large portion of the PC1 score spectrum, with little separation between them. The only exceptions were some crocodyloid teeth below PC1 scores of -0.2. Both Borealosuchus sternbergii tooth rows had PC1 scores between -0.22 and 0.20 , and Hamadasuchus rebouli ranged between -0.19 and 0.23 . These were nested within the 
329 alligatoroids and crocodyloids. Gavialis gangeticus deviated from the rest in that most teeth

330 had PC1 scores of <-0.20 (Figure 2B). PC2 scores did not differ between groupings of taxa, as

331 each group occupied most of the shape range.

\section{Skull vs. tooth morphology}

333 Skull and average tooth shape were significantly correlated. For the two-block PLS test, PLS1

334 encompassed $99.96 \%$ of total covariation and had a correlation coefficient of 0.7937 . Shape

335 variability within the skull shape block showed the snout transitioning from narrow to broad

336 (Figure 3A). Taxa that occurred below a PLS1 score of -0.15 were the slender-snouted taxa as

337 defined by Brochu (2001), including Gavialis gangeticus, Mecistops cataphractus, and

338 Tomistoma schlegelii. The remainder of the species, defined as either generalized or blunt-

339 snouted (also by Brochu, 2001), occurred around the mean and positive half mixed together.

340 Shape variability within the tooth shape block was similar to the above PCA of tooth shape,

341 displaying a transition from caniniform to molariform with increasing values (Figure $3 \mathrm{~A})$. These

342 blocks regressed significantly against one another (Figure 3B), with slender-snouted taxa

343 separating out with the most caniniform teeth. Scatter increased around the means, indicating

344 the correlation was not as strong among the generalized-to-blunt snouted taxa. Alligator

345 prenasalis, Brachychampsa sp., and "Crocodylus" affinis were all relatively blunt-snouted, but

346 rose noticeably above the regression. This suggested they possessed much more molariform

347 teeth on average than their counterparts of similar skull shape.

\section{Foote's disparity and heterodonty}


349 Size-heterodonty was significantly correlated with skull length, with an $r^{2}$ of 0.760 . The largest

350 individuals according to skull length (members of Crocodylus niloticus and Crocodylus porosus)

351 possessed the greatest unadjusted size-heterodonty (Figure 4A). Members of Alligator had

352 negative residual size heterodonty, with Alligator prenasalis as the lowest. On the other side of

353 the regression, residuals of caimanine specimens (Caiman, Paleosuchus) were all positive with

354 the exception of one individual. Several members of Crocodylus had values around or below

355 zero, but one Crocodylus porosus specimen had a high residual. One Osteolaemus tetraspis

356 individual had the highest size-heterodonty residual, with the other close to the regression.

357 Hamadasuchus rebouli had positive residuals, similar to the larger Crocodylus porosus and the

358 caimanine specimens. The slender-snouted taxa (Gavialis gangeticus, Mecistops cataphractus,

359 Tomistoma schlegelii) had some of the more negative residuals. For the regression excluding

360 individuals with less than $70 \%$ of either tooth row represented, the regression statistics

$361\left(y=2.208 x-8.583 ; r^{2}=0.770 ; p<0.0001\right)$ were strikingly similar to those of the complete dataset

$362(y=2.196 x-8.549 ; r 2=0.760 ; p<0.0001)$. poor correlation $\left(r^{2}=0.157\right)$, with skull length (Figure 4B). Similar to size-heterodonty, the slender-snouted taxa had some of the lowest shape-heterodonty, although Tomistoma schlegelii was greater than several other taxa. In addition, members of Brachychampsa sp. and Alligator prenasalis also had some of the lowest shape-heterodonty in our sample. Crocodylus siamensis specimens were more shape-heterodont than their congenerics, with one individual being the most shape-heterodont in our sample. Several caimanine individuals, and both 
371 regression excluding individuals with less than $70 \%$ of either tooth row represented, regression

372 statistics $\left(y=-0.648 x-0.235 ; r^{2}=0.238 ; p<0.0397\right)$ were also similar to those of the complete

373 dataset $(y=-0.715 x-0.172 ; r 2=0.157 ; p<0.0223)$.

\section{Heterodonty along the tooth row}

375 Tooth position count varied between species (see Supplemental Information Table S2). Most

376 alligatoroids had between 19-20 positions on the cranial tooth row. Many had a similar number

377 on the dentary, except that members of Paleosuchus had 22 positions. Leidyosuchus canadensis

378 had the most (23) cranial positions of the alligatoroids. Hamadasuchus reboulii (20 cranial) and

379 Borealosuchus sternbergii (23 cranial and 20 dentary) specimens fit within ranges of

380 alligatoroids. Members of Crocodylus and Mecistops cataphractus had between 18-19 cranial

381 and 15 dentary positions. Osteolaemus specimens had the least tooth positions for any

382 crocodyloid (17 cranial and 14 dentary), and Tomistoma schlegelii had the most (21 cranial and

38319 dentary). The Gavialis gangeticus specimen had more positions than any other species

384 sampled ( 28 cranial and 26 dentary). These tooth counts are similar to previous published

385 accounts (Brown et al., 2015; Berkovitz \& Shellis, 2017).

In all taxa combined, ANOVA indicated size differed significantly between tooth positions $[F(34,261.45)=4.57 ; p<0.0001]$. In Alligatoroidea and Crocodyloidea, size undulated three times along the dental arcade resulting in significant differences between positions for both the cranium and mandible (Figure 5A-B). Each undulation peaked with an enlarged tooth. These were typically represented by P4 for both clades, and M4 for alligatoroid and M5 for 
392 had very large P3 and M3. "Crocodylus" affinis also had a large P3. Unlike other alligatoroid specimens, Leidyosuchus canadensis had both M4 and M5 enlarged, and the Brachychampsa sp. had an enlarged M5 like crocodyloids (sensu Norell, Clark, \& Hutchison, 1994). A final undulation resulted in an enlarged tooth at M9-11 (Figure 5A-B). Interspersed between these were smaller teeth, with the distal-most tooth often the smallest. The dentary was similar to the cranium, with three undulations in size. Enlarged teeth were found at positions D1 and D4, with a third size-peak between D11 and D14. Note that the position of the enlarged teeth along the cranial tooth row tended to align with smaller teeth along the dentary tooth row, and vice versa. This resulted in an 'adjoining' pattern between the size peaks of one arcade and the valleys of the other. The gavialoid specimen differed markedly by having the two mesial-most teeth enlarged, and the remainder showed a gradual decease in size distally (Figure 5C). Hamadasuchus rebouli had some of the largest teeth for its skull length with a dramatic variation in size. $\left[F(4046,23939.54)=1.27 ; p<0.0001 ;\right.$ Wilk's $\Lambda=0.002 ;$ partial $\left.\eta^{2}=0.171\right]$, although in a visibly different fashion than size. We only graphed PC1 scores against tooth position, as the other PCs represented under $5 \%$ of the variance each and were not considered biologically relevant to tooth position (for a justification, see Supplemental Information). Alligatoroids and crocodyloids both had mesial teeth that were typically the most caniniform in the mouth, and distal teeth the most molariform (Figure 5D-E). In cranial teeth P1-M4 tend to exist primarily between PC1 scores of -0.25 and 0.00 , followed by a gradual increase in score values as positions become more distal. Dentary teeth represented a more uniformly gradual caniniform-to-molariform 
414 transition. Both superfamilies were highly variable. Alligatoroidea had teeth generally more 415 molariform, with upper outliers almost entirely represented by Alligator prenasalis, Alligator 416 sinensis, and Brachychampsa sp. (Figure 5D). Crocodyloidea was generally more caniniform, 417 with mesial upper outliers represented by "Crocodylus" affinis and lower outliers represented 418 primarily by Tomistoma schlegelii (Figure 5E). Both Borealosuchus sternbergii tooth rows had 419 PC1 scores between -0.22 and 0.20 , and Hamadasuchus ranged between -0.19 and 0.23 (Figure

420 5F). Both taxa showed a similar progression from caniniformy to molariformy as the

421 alligatoroids and crocodyloids. Gavialis gangeticus deviated from the others the most, where 422 most teeth had scores of $<-0.20$ with a steep increase towards the average in the distal-most 423 fifth of the arcade (Figure 5F). Tooth shape was strongly influenced by tooth position (Figure 6). When each modern 425 individual's PC1 values were regressed against position, all linear regressions were significant 426 (Supplemental Information Table S2). The vast majority of tooth row regressions had $\mathrm{r}^{2}$ values 427 above $80 \%$. Gavialis gangeticus had the lowest $r^{2}$ values (cranium $=0.495$, mandible $=0.616$ ), 428 followed by the crania of the fossil Caiman crocodilus $\left(r^{2}=0.728\right)$ and Tomistoma schlegelii $429\left(r^{2}=0.747\right)$. Both cranial and dentary tooth rows typically had slopes between 0.25-0.55 (Figure 430 6). More shape heterodont taxa typically had greater slopes, with Crocodylus siamensis 431 specimens having some of the steepest slopes $(0.39-0.68)$. All the slender-snouted specimens 432 had the $y$-intercepts between -0.25 and -0.14 , indicating strong caniniformy at the median position. Living members of Alligator had $y$-intercepts between 0.029 and 0.085 , indicating 434 molariformy at the median (Figure 6). Alligator prenasalis, Brachychampsa sp., and "Crocodilus" 435 affinis had the shallowest slopes (0.22-0.32) and the greatest $y$-intercepts $(0.15-0.24)$ in our 
436 sample, indicating molariform teeth are consistent along the tooth row. Hamadasuchus

437 rebouli's regression characteristics are similar to members of Caiman and Osteolaemus

438 tetraspis. The slope of the fossil Caiman crocodilus differed from modern members of Caiman

439 by being much shallower (Figure 6).

\section{DISCUSSION}

\section{Defining heterodonty within Crocodylia}

442 The methods proposed here offer a multi-faceted approach to quantifying heterodonty in

443 Crocodylia. As was first proposed in D'Amore (2015), outlining the margin of the tooth is a

444 comprehensive method for measuring two-dimensional tooth shape. This type of semilandmark

445 analysis is ideal for any cylindrical, conical, caniniform, or ziphodont dentition, and would

446 include many archosaurs, squamates, sauropterygians, ichthyosaurs, teleosts, sharks, etc. As

447 tooth morphology is often compared between taxonomically disparate groups (examples in

448 Ciampaglio et al. 2005; Foffa et al., 2018), future studies should use semilandmark analyses to

449 compare crocodylians to these groups to answer numerous phylogenetic and ecomorphological 450 questions.

$451 \quad$ Foote's morphological disparity allows for a continuous and quantitative measure of

452 heterodonty that may be used for comparison between taxa, or compared with other variables

453 (as was done here with skull length). This measure is ideal if one is interested in how much

454 heterodonty is apparent. Alternatively, if one is interested in what shape characteristics make

455 up tooth heterodonty, ordination approaches suffice in describing shape variability. Although

456 plotting PC scores as Cartesian coordinates in a morphospace is traditionally done to visualize 
457 shape variability (as in Figure 2B), overlap due to shape-heterodonty makes specimens, species,

458 and even superfamilies almost indistinguishable from one another. This exemplifies why

459 methods such as box plots and linear regressions may be preferable over the more 'standard'

460 morphospace depiction when heterodonty is concerned. It is convenient that only PC1

461 accounted for over $90 \%$ of the variance, allowing for us to use it as the sole measure of shape

462 here. If more PCs accounted for over $5 \%$ of the shape variance, it would be appropriate to

463 depict those other PCs in the same manner as PC1 for a comprehensive understanding of

464 shape.

Regression analysis of shape against position generally yielded strong correlations

(Supplemental Information Table S2), and the resulting coefficients were useful for comparison

467

468

469

470

471

472

473

between individuals. Certain caveats should be considered though. Regression may be more appropriate for the dentary than the cranium, because in the cranial arcade the mesial-most teeth do not appear to differ from one another as much as the remainder. In most crocodylians this effect is mild, and $r^{2}$ values are still high. The effect is very pronounced in Gavialis gangeticus though, as both the premaxillary and most maxillary teeth are similar in shape. It is also interesting that this happens in the dentary as well. Future studies should consider this when applying this method to Gavialoidea or dentally analogous taxa.

Although the task of assigning a singular dental morphotype to any one species of crocodylian is beyond the scope of the study, our data suggest that it would be potentially difficult. Heterodonty seems to vary within species, making the assignment of a singular heterodonty measure to an entire species dubious. As far as biological explanations for this, 
478 tooth form is almost certainly influenced by allometry. Ontogenetic shifts in feeding niche have 479 been documented in modern crocodylian species (e.g. Groombridge, 1982; Webb, Manolis, \& 480 Buckworth, 1982; Pooley \& Gans, 1976; Pooley, 1989; Delany, 1990; Santos et al., 1996; Da 481 Silveira and Magnusson, 1999; Subalusky, A. L., Fitzgerald, L. A., \& Smith, 2009 Wallace and 482 Leslie, 2008; Borteiro et al., 2009; Hanson et al., 2014), and allometric changes in the feeding 483 apparatus with size are often explained as a structural consequence of this (e.g. Dodson, 1975; 484 Webb and Messel, 1978; Hutton, 1987; Erickson, Lappin, \& Vliet, 2003; Verdade, 2000; Wu et 485 al., 2006; Watanabe \& Slice, 2014; Gignac and Erickson, 2016; Gignac \& O’Brien, 2016). 486 Concerning teeth, a qualitative increase in overall molariformy was observed in Alligator 487 mississippiensis, as it functioned to meet the mechanical demands of increased durophagy 488 (Erickson, Lappin, \& Vliet, 2003; Gignac \& Erickson, 2014). Although our sample size is too low 489 to confidently assess dental ontogeny within each species, we did see a similar general trend in 490 conspecifics of different sizes. In particular, the larger of our two Crocodylus porosus had a 491 greater $y$-intercepts indicating greater molariformy. Although there was no significant effect of captive rearing on our specimens, we believe this principle should still be investigated further. Some cases of captive rearing have resulted in very different, and easily distinguishable, cranial morphologies, but there is also quite a bit of overlap concerning others (Drumheller, Wilberg \& Sadleir, 2016). This may, or may not, happen with teeth. A larger data set, looking at multiple ontogentic stages, is necessary to determine if rearing condition has any measurable effects on teeth. The method proposed here would allow for the rigorous comparison between these two rearing conditions, and determine if any changes do occur as well as other factors may correlate to said changes. 


\section{Morphological trends within Crocodylia}

501 All crocodylian specimens measured here were heterodont to varying degrees, and these data

502 showed significant variability of morphotypes along the dental arcade for all specimens (Figure

503 7). Although dentition varied between species, certain consistencies were seen throughout the 504 clade:

1. Similar teeth occurred on both the cranial and dentary dental arcades.

2. As body size increased, size-heterodonty increased reliably with it. Shape-heterodonty shows a much less reliable negative correlation with body size.

3. The vast majority of shape variance from the labial perspective occurred along a single shape axis, representing the transition from caniniform to molariform.

4. There was serial homology in tooth shape from-mesial-to-distal along the tooth row, and molariformy increased in this direction. The transition was significantly linear for both dental arcades in all specimens.

5. Size variability consisted of a non-linear, undulating pattern with three peaks that adjoin with the opposing row, with enlarged crowns interspersed within smaller crowns. This corresponded with the festooning pattern seen in the tooth bearing bones, and was less

517 Size- and shape-heterodonty were very loosely coupled in Crocodylia as they changed in did occur; the regression's significance was probably the result of the fact that the distal-most crowns were typically both the smallest crowns as well as the most molariform. Nevertheless, 
521 the undulating pattern of tooth size did not align with linear shape heterodonty for the vast

522 majority of the tooth row, as indicated by the very low $r^{2}$.

523 The low degree of coupling begs the question; do developmental agents influence size

524 and shape separately? Although quite a bit of research has looked at how crocodylian teeth

525 grow and replace themselves (Edmund, 1962; Westergaard and Ferguson, 1986, 1987, 1990;

526 LeBlanc et al., 2017), surprisingly little has been done on what developmental influences affect

527 tooth size and shape. Modern crocodylians replace their teeth in waves, or Zahnreihe (Edmund,

528 1962; Westergaard and Ferguson, 1990; Osborn, 1998), but it is unclear how the nature of

529 these waves relate to the morphological variables investigated here. Keiser et al., (1993)

530 compartmentalized the dentition along the tooth row for Crocodylus niloticus, grouping teeth

531 into 'incisor,' 'premolar,' and 'molar' regions. These designations attempted to account for both

532 size and shape heterodonty; each was defined by an enlarged tooth, and each become

533 progressively more molariform. They did not offer a developmental mechanism that

534 differentiated these categories though. Fruchard $(2012$, p.7) suggested that the only difference

535 between enlarged teeth and their smaller counterparts was that the former was "programmed

536 to be bigger," suggesting some sort of additional developmental signaling to enlarge teeth.

537 More research is needed on how tooth shape and size are established developmentally in order

538 to truly understand what generates heterodonty. crocodylians was particularly revealing. This indicated the methods proposed here may be

541 transferable to at least some crocodyliforms outside of Crocodylia. It should also be noted that 
542 this consistency exists in spite of the numerous craniodental characteristics that differ between

543 Hamadasuchus rebouli and the crocodylians, including a deep-snout and ziphodont teeth

544 (Larsson \& Sues, 2007). The characteristic heterodonty may be covergently derived or

545 homologous with what is seen in this peirosaurid, and further research should investigate how

546 frequent it is seen in Crocodyliformes as a whole.

547 Adaptive explanations for morphological variability in modern taxa

548 There is a wide range of tooth morphologies present in modern Crocodylia, and, as teeth are

549 anatomical units used for feeding and aggression, functional inferences may be drawn based on

550 our present understanding of behavior and performance. Bite force in crocodylians is primarily

551 influenced by size (Erickson et al., 2012, 2014), and our data set shows that similarly sized

552 crocodylians may have very different tooth dimensions. This rules out adductor-generated

553 maximum bite force as the sole limiting factor dictating tooth form. Although we are reluctant

554 to associate specific prey items with specific tooth forms, size and shape will influence how a

555 tooth interacts with food items possessing certain physical properties. We therefore suggest

556 that a biomechanical link should exist between the structural limits imposed by tooth form and

557 the material properties of the substrates with which it interacts.

As with all jawed vertebrates, crocodylian teeth will succumb to different speeds and

pressures based on their respective position along the arcade. Caniniform mesial teeth are ideal

560 for the initial acquisition of prey. Pointed apices reduce surface area to puncture compliant

561 foods that deform under pressure, such as muscle, fat, and fibrous connective tissue (Frazetta,

562 1988). Being farther from the hinge, these teeth move faster during a strike and are more likely 
563 to contact prey trying to escape (Busbey, 1989). They will also endure less pressure during a

564 bite based on their position (Erickson et al., 2012), and can afford to be relatively elongate and

565 gracile. On the other end, distal teeth need to withstand greater tooth pressures due to their

566 close proximity to the hinge (Cleuren, Aerts, \& Vree, 1995; Erickson, Lappin, \& Vliet, 2003;

567 McHenry et al., 2006; Erickson et al., 2012). This explains why these teeth are typically on the

568 molariform half of the shape spectrum; the larger base-to-height ratio gives them greater

569 relative bending strengths to withstand said pressures (Van Valkenburgh and Ruff, 1987; Gignac

570 \& Erickson, 2014; Monfroy, 2017). Because force is highest in this region, it is ideal for

571 processing food items after they are acquired (Busbey, 1989; Davenport et al., 1990; Cleurens

572 and de Vree, 2000). The reduced height of these teeth also ensures they do not impede jaw

573 closure. This necessity is very apparent in our representative member of Gavialis gangeticus,

574 and provides a functional explanation for the poor linear shape relationship along the tooth

575 row in this individual. Having all the teeth be highly caniniform except for the distal-most region

576 may be interpreted as an attempt to reduce heterodonty as much as possible (Grigg and Gans,

577 1993), while ensuring the distal crowns do not impede jaw closure or break when processing

578 food.

579

Particular attention should be paid to the relative size of the distal-most crowns, as they vary considerably within our sample. Most modern alligatoroids and crocodyloids have a single enlarged tooth followed distally by several smaller teeth on the caudal half of their jaw. These teeth typically had positive PC1 scores, especially within Alligator mississippiensis and

584 Members of Alligator sinensis differed from this though, in that they had a row of 4-5 relatively 
585 large, high-molariform crowns (followed by only one crown reduced in size). Probably the most 586 extreme condition, Osteolaemus tetraspis specimens had distal crowns that were exceptionally 587 large; the largest relative crowns at positions M10-12 and D11-13 for modern taxa all belonged 588 to members of this species. These two species also have the lowest number of teeth for 589 modern alligatoroids and crocodyloids respectively, a reduction potentially based on the need to fit these enlarged teeth. Aoki (1989) qualitatively noted these unique conditions, and 591 suggested they facilitated durophagy. All alligatoroids and crocodyloids sampled here have 592 been recorded to consume at least some hard prey items though (e.g. Brazaitis, 1973; 593 Mcllhenny, 1976; Taylor, 1979; Groombridge, 1982; Ross and Magnusson, 1989; Santos et al., 1996; Selvaraj, 2012; Nifong \& Silliman, 2013), so it is unclear what selection pressure resulted in these particular morphologies. It may be a result of body size. Bite force tests of Alligator mississippiensis showed the pressure produced at its enlarged M11 to be adequate to crush its harder prey items (Erickson, Lappin, \& Vliet, 2003; Gignac \& Erickson, 2014). If this is the case in most of the large crocodylians, enlarging the distal-most crowns would be unnecessary. Alligator sinensis and Osteolaemus tetraspis, on the other hand, may need more extreme dentition closer to the hinge; their smaller size would make it more difficult to process foods with similar mechanical properties. Another explanation for this may be the frequency of consuming hard prey. Although both these species have broad diets, studies have shown certain (but not all) populations of these species to consume disproportionately large numbers

604 of shelled mollusks and crustaceans (Cheng-Kuan, 1957; Groombridge, 1982; Ross and 605 Magnusson, 1989; Luiselli, Akani, \& Capizzi, 1999; Pauwels et al., 2007). 
All taxa measured here also have two sets of enlarged mesial teeth on both arcades.

607 These teeth are well built for puncturing, likely making first contact with prey during jaw 608 closure, and are resilient against struggling prey (lordansky, 1964). An apparent trade-off to 609 enlarging these teeth is the need to reduce the size of teeth on the opposing tooth row. This character played a large role in size-heterodonty, with different crocodylians undulating their

611 tooth sizes to different degrees. High relative size-heterodonty in specimens found within

612 Caimaninae was typically a consequence of the dramatic size difference between the enlarged teeth and the small remaining crowns, (Figure 7B). Their dentary crowns in particular became so large they often grew entirely through the cranial rostrum in adults (as mentioned in

615 Brazaitis, 1973), which suggests securing prey takes priority. The remaining crowns were rather 616 small by comparison, including the distal crowns: the teeth with the greatest mechanical 617 advantage when processing hard prey. This overall condition may be specialized for hunting 618 more mobile and/or compliant prey, as these types of prey may be punctured quickly and 619 securely with the enlarged, pointed crowns (Sampaio et al., 2013). The Crocodylus porosus 620 specimens had the largest M5 crowns in our sample, which may also show a prioritization for 621 puncturing and securing soft-bodied prey in a larger context (Figure 7B). This species is 622 notorious for actively hunting large vertebrates such as sharks, cattle, horses, and humans (e.g. 623 Taylor, 1979; Kar \& Bustard, 1981; Groombridge, 1982; Doody, 2009; Hanson et al., 2015), and 624 these teeth are ideal for puncturing and securing such prey. Similar to the caimanine 625 specimens, this species atrophies position P2 to make room for its enlarged D1 crowns (Brown 626 at al., 2015) 

jaw adduction when feeding underwater, and the increased snout length allows for a faster strike (Taylor, 1987; Pooley, 1989; Thorbjarnarson, 1990; McHenry et al., 2006; Pierce et al., 2008). Highly caniniform teeth can quickly puncture fast-moving, compliant prey, and their elongate shape may also lower their mechanical resistance (Figure 7C). The longirostrine condition, defined as a snout that is both slender and elongate (Brochu, 2001), resulted in increased tooth positions; Tomistoma schlegelii had more teeth than any other crocodyloid, and Gavialis gangeticus has the most teeth out of all crocodylians sampled. This cranio-dental morphotype may be prey-size prohibitive though, as larger prey could damage the slender rostrum while struggling. Their elongate mandibular symphysis results in a mechanical

642 The gracile nature of the dentition means a lower bending strength, making them more susceptible to breakage from larger and/or harder prey as well. On rare occasions, large individuals have been known to take land-based, vertebrate prey (Thorbjarnarson, 1990;

646 their feeding apparatus to withstand the forces exerted by said prey. 
649 share certain traits with the anisodont plesiosauromorphs (Sassoon et al., 2015; Kear et al., 650 2017). Although these crocodylians are not anisodont in the strict sense (they all have some 651 shape heterodonty), both taxa have elongate mesial crowns transitioning to smaller distal ones.

652 These taxa also reflect similarities with the 'homodont' condition apparent in odontocete 65 whales (Rommel, 1990), where all the teeth in the arcade possess a similar, peg-like shape. This 654 condition is believed to be ideal for catching and holding, but not processing, small aquatic prey 655 (MacLeod et al., 2007), as most prey items consumed are under $10 \%$ of their body length 656 (MacLeod et al., 2006). A convergent reduction in size- and shape-heterodonty within these 657 independently aquatic groups may indicate a transition from a multi-functional dental arcade to 658 one almost exclusively for prey capture. This morphological condition is best exemplified by 659 Gavialis gangeticus, as it is almost entirely caniniform along its tooth row and eats primarily fish 660 (Groombridge, 1982, Figure 7C). Members of Mecistops cataphractus and Tomistoma schlegelii, 661 although also primarily caniniform, still displayed the linear shape change typical of other 662 crocodyloids. These species may consume prey that require relatively more processing with their distal crowns, and there are numerous reports of them eating prey such as crustaceans, turtles, and immature primates (Brazaitis, 1973; Groombridge, 1982; Galdikas and Yeager, 665 1984; Selvaraj, 2012). though overlap exists in prey selection. Alligator mississippiensis and Crocodilus niloticus both consume a wide variety of prey, including both large and small mammals, crustaceans, fish, water fowl, snakes, turtles, and conspecifics (Mcllenny, 1976; Pooley \& Gans, 1976;

670 Groombridge, 1982; Delany and Abercrombie, 1986; Hutton, 1987; Shoop \& Ruckdeschel, 1990; 
671 Rootes \& Chabreck, 1993; Elsey, Trosclair III, \& Linscombe, 2004; Wallace and Leslie, 2008;

672 Gabrey, 2010). A comparison of controlled feedings of each of these species showed Alligator

673 mississippiensis to fracture and consume noticeably more bovine skeletal elements than

674 Crocodylus niloticus (Njau \& Blumenschine, 2006; Drumheller \& Brochu, 2014; 2016). Our

675 Alligator mississippiensis specimens was generally more molariform than Crocodylus niloticus.

676 These teeth would have greater bending strengths to resist breakage when processing hard

677 material such as bone.

678 Fossil taxa and the appropriateness of analogues

679 Certain fossil taxa were reminiscent of modern counterparts. We expected the fossil Caiman

680 crocodilus to be similar to its congenerics, due to the fact that these specimens are closely

681 related and all consume insects, crustaceans, and fish (Brazaitis, 1973; Groombridge, 1982; Da

682 Silveira and Magnusson, 1999). Any differences in size and shape ranges appear to simply be a

683 consequence of the former's incomplete arcades; no distal maxillary or dentary crowns were

684 available (see Limitations below). Alligator mississippiensis specimens have similar shape

685 regression statistics to our Leidyosuchus canadensis specimen, but, unlike members of Alligator,

686 this specimen lacked enlarged distal teeth (Figure 7D). This caused size heterodonty to differ

687 noticeably, and may be indicative of a difference in the degree these taxa process hard

688 materials (although no taphonomic evidence for this currently exists associated with

689 Leidyosuchus canadensis). The two specimens of Borealosuchus sternbergii differed from one

690 another in median shape as indicated by $y$-intercepts, which may due to an allometric increase 
691 in molariformy. The best analogue for this species may be a member of Crocodylus with similar

692 slopes such as Crocodylus palustris, but more data are necessary to confirm this (Figure 7D). similar prey from a mechanical standpoint (Figure 7E). The greatly enlarged mesial teeth would puncture vertebrate tissue with similar effectiveness (Figure 7B). Hamadasuchus rebouli differed in that it had very large distal crowns, which, unlike Osteolaemus tetraspis, are laterally flattened (Larsson \& Sidor, 1999). This suggests potential differences in prey processing.

Peirosaurids are believed to be primarily terrestrial crocodyliforms (Tavares et al., 2017), and they most likely did not occupy the semi-aquatic, sit-and-wait predator niche dominated by modern crocodylians (Larsson \& Sues, 2007). It may have used these for either sheering soft tissue or breaking bone similar to modern mammalian carnassials, as rolling on land is not an effective means of dismemberment (Fish et al., 2007). extreme degree of molariformy commonly found in extinct representatives. 'Globidonty' describes the enlarged, highly molariform crowns in fossil taxa potentially used for durophagy (Norell, Clark, \& Hutchison, 1994; Brochu, 1999; 2001; Ősi \& Barrett, 2011). Species of Brachychampsa are textbook examples of a globidont taxa (Case, 1925; Carpenter and Lindsey, 1980, Figure 7F), and our specimen is the only one in the sample with distal teeth so molariform their PC1 scores exceed 0.349. Although we agree with Brochu $(2001,2004)$ that Osteolaemus

711 tetraspis is not as extreme, the PC1 scores of its enlarged distal teeth are closer to our 
712 Brachychampsa sp. than any other taxon sampled (0.322-0.341). Alligator prenasalis and

713 "Crocodylus" affinis distal crowns are similar to Alligator sinensis in shape, and also create a

714 ridge of robust teeth (Mook, 1932). The mechanical capabilities of these particular crowns in

715 modern taxa should be similar to the extinct, which suggests similar processing abilities in the

716 distal regions of the skull. The similarities break down when the rest of the jaw is considered

717 though. In addition to these highly molariform teeth, modern taxa also possess caniniform

718 mesial teeth suggesting a division of labor along the tooth row. Contrarily, almost all teeth of

719 members of Alligator prenasalis, Brachychampsa sp., and "Crocodylus" affinis are on the

720 molariform half of the shape-spectrum (Figure 7F), making both their size- and shape-

721 heterodonty rather low. These extinct taxa probably did not need to do as much puncturing of

722 compliant substrate, which supports the argument that they may have foraged for mollusks and

723 slow moving turtles (Carpenter and Lindsey, 1980; similar to Salas-Gismondi et al., 2015) rather

724 than being ambush predators.

\section{Limitations and future work}

726 A complete tooth row with all positions represented would be the most thorough way to assess

727 heterodonty in any specimen. Nevertheless, complete tooth rows may not be available under

728 many circumstances. Although we cannot propose a threshold for what number of teeth is

729 'enough' to accurately assess heterodonty, there are factors that influence some of these

730 methods more than others. Foote's morphological disparity relies on, among other things, the

731 grand mean and the sample size. Size-heterodonty may be underrepresented if, for example, an

732 enlarged tooth is missing. This tooth would deviate greatly from the grand mean if present, so 
733 its exclusion would deflate size heterodonty. Due to their greater frequency, small teeth would

734 typically be closer to the grand mean. Therefore, if a single small tooth was missing

735 heterodonty would slightly inflate. It should also be noted that if the majority of small teeth

736 were missing their absence would end up decreasing heterodonty, as the grand mean would

737 approach the value of the remaining large teeth. Shape-heterodonty will not be as influenced

738 by enlarged teeth missing, but more so by a lack of the mesial- or distal-most teeth. Missing

739 many of the caniniform or molariform teeth will deflate shape-heterodonty, as the overall

740 variance would be reduced. This would also influence regression statistics, as a lack of either

741 extreme would raise or lower the slope and/or $y$-intercept.

Even though our data set included several specimens with tooth rows with less than

$70 \%$ completeness, we feel our data is reliable enough for the morphological and functional

conclusions we draw. The similarity between the heterodonty regressions representing all

specimens, versus those with more complete specimens only, suggests that incompleteness did

not influence our heterodonty values very much. This is most likely because the factors that

would strongly influence size- and shape-heterodonty mentioned above were relatively rare in

our data set. Few specimens sampled lacked enlarged teeth. The teeth that were missing were typically spread throughout the tooth row, and not localized to the mesial or distal extremes.

There were several specimens whose heterodonty results were probably strongly influenced.

751 The very low size-heterodonty in Alligator prenasalis may be a consequence of the loss of enlarged teeth, but the relatively small P4 crown suggests this value should be on the low-end regardless. The fossil Caiman crocodilus was also affected by missing teeth. It shared almost

754 identical tooth morphology with modern congenerics at similar positions. Because the distal 
$75530 \%$ of its teeth were missing, Foote's disparity of shape was reduced. This also affected the

756 shape regression, as the lack of high PC1 scores on the distal end reduced the slope. Although

757 both Crocodylus siamensis specimens have very high shape-heterodonty due to having both

758 very caniniform and molariform crowns along their arcade, one specimen (AMNH 49231)

759 yielded a very high shape disparity value. This was most likely partially influenced by missing

760 teeth.

761

The two-block PLS test did not factor in heterodonty. Although this was not the goal of

762 this particular analysis, it should be noted that the averaged tooth used for one block

763

essentially eliminates variability of tooth shape along the arcade. Specimens with both low and

high shape-heterodonty could produce very similar averages. This highlights the pitfalls of simply averaging all the teeth in the arcade together for the purposes of understanding dental morphology, and why it is avoided in our assessments of heterodonty here.

We did not consider all three dimensions. Living crocodylian teeth are often described as conical (Edmund, 1969) or conidont (Hendrickx, Mateus, \& Araújo, 2015b). Studies of bending strengths show variation between mesial-distal and labial-lingual axes (Monfrey, 2017), indicating that functional information may be drawn from the dimension not measured here. This is especially important concerning fossil taxa, as pronounced lateral compression is commonplace. Hamadasuchus rebouli distal teeth have been referred to as ziphodont (Larsson avoid conflating disparate tooth morphotypes such as these. 
nature of the sample. Although they are very revealing concerning shape variability, they are not transferable between different data sets. A potential method for creating transferable shape metrics is using our PC1 axis as a guide to derive linear distance measures that would account for the serial shape homology seen in Crocodylia. Since PC1 essentially represents molariformy vs. caniniformy from the labial perspective, it could possibly be simplified into a comparison of linear distance measures such as maximum mesial-distal widths and apical-basal heights. These metrics would be not only easy to collect, but also transferable between data sets. non-mammalian taxa. As stated above the semilandmark analysis is very versatile, especially for single-cusped teeth. Foote's disparity can be applied to any measurable taxon with a complete enough tooth row, and is transferable between even disparate groups. Mesial-to-distal linear regressions may be directly applied to any crocodylian, and perhaps certain crocodyliform, specimens with an intact enough tooth row. This could also be applied to PC scores in other non-mammalian taxa, to determine what degree (if any) shape change is linear. other factors such as ontogenetic changes (Erickson, Lappin, \& Vliet, 2003; Erickson et al., 2004; investigated in the future using our method, as there is nothing to suggest that crocodylian individuals of most species and/or ages could not be be quantified in a similar manner. This 
797 method could be very useful in dealing with incomplete fossils. It is common for fossil

798 crocodylian specimens to be lacking many, or even most, of their teeth. The linear nature of

799 tooth shape can predict the shape of these missing teeth. A record of the ranges of slopes may

800 be accumulated for fossil specimens with intact teeth. These slopes may then be used as a

801 reference, and be applied to a fossil with the missing teeth. The preserved teeth can be plugged

802 into the linear equation, and the shapes of missing teeth may be predicted with a high degree

803 of certainty. This would result in a more complete representation of the extinct animal's

804 anatomy, useful from the standpoint of both anatomical science and paleontological

805 reconstruction.

Quantifying the teeth of Crocodylia will add rigor to future life history studies of the

807 clade. First and foremost, values may be applied to the plethora of qualitative terms used by

808 researchers (see Introduction). This would allow for stricter definitions of the terms when used

809 in the future. As a quantifiable trait, both tooth shape in a single position and heterodonty as a

810 whole may be incorporated into character matrices for phylogenetic analyses. Quantitative

811 descriptors of dentition can describe a numerical range of morphology as opposed to cherry-

812 picking an average tooth or single position. The teeth of fossil taxa can be compared statistically

813 to modern taxa to determine the best analogue, and rigorous hypotheses about paleobehavior

814 and paleoecology may be drawn. Crocodylia, both living and extinct, may be grouped into

815 dental categories, allowing for species and specimens to be compared to one another (similar

816 to snouts in Brochu, 2001). Frequency, size, and hardness of food items may be compared to

817 these categories to determine if a link exists between dental morphotypes and dietary patterns

818 (similar to Aoki, 1989). Crocodylians are used in both performance and actualistic taphonomy 
819 studies frequently (Njau \& Blumenschine, 2006; Erickson et al., 2012, 2014; Drumheller \&

820 Brochu, 2014; 2016), and the output of these studies could be correlated with tooth

821 dimensions. Tooth shape may also be compared to bite-force, death-rolling, bone-modification,

822 and prey preferences and mechanical properties.

\section{CONCLUSION}

Multiple measures of morphology have allowed us to describe heterodonty in a

thorough manner across a number of both extinct and extant crocodylian specimens. Through a

combination of Foote's morphological disparity and regression analysis along the tooth row,

our data indicates that crocodylians are indeed heterodont with a number of dental

morphotypes available spanning from extreme cases of caniniform to molariform. This

variability may be functional in nature, and relate to the size, frequency, and compliance of

certain prey in their typically generalist diets. The methods used here should be applied in the

future to most crocodylian specimens, as well as other non-mammalian tetrapods, to

investigate dental morphology in the context of a number of natural history related questions.

\section{Acknowledgements}

834 The American Museum of Natural History Department of Herpetology, Royal Ontario Museum

835 Vertebrate Paleontology, and University of California Museum of Paleontology curatorial staff

836 allowed on-site access to dry skull specimens. We would like to particularly thank D. Evans, P.

837 Holroyd, D. Kizirian, C. Raxworthy, K. Seymour for their assistance. 


\section{References:}

839 Adams TL, Noto CR, Drumheller S. 2017. A large neosuchian crocodyliform from the Upper Cretaceous (Cenomanian) woodbine formation of North Texas. Journal of Vertebrate Paleontology 37(4):e1349776.

Aoki R. 1989. The jaw mechanics in the heterodont crocodilians. Current Herpetology in East Asia 1:17-21.

Bennett GE. 2012. Community structure and paleoecology of crocodyliforms from the upper Hell Creek Formation (Maastrichtian), eastern Montana, based on shed teeth.

Berkovitz BK, Shellis RP. 2017. The Teeth of Non-mammalian Vertebrates. Cambridge, MA: Academic Press.

Bookstein FL. 1997. Morphometric tools for landmark data: geometry and biology. Cambridge: Cambridge University Press.

Borteiro C, Gutiérrez F, Tedros M, Kolenc F. 2009. Food habits of the Broad-snouted Caiman (Caiman latirostris: Crocodylia, Alligatoridae) in northwestern Uruguay. Studies on Neotropical Fauna and Environment 44(1):31-36. Society. 
856 Britt EJ, Clark AJ, Bennett AF. 2009. Dental morphologies in gartersnakes (Thamnophis) and 857 their connection to dietary preferences. Journal of Herpetology 43(2):252-259.

858 Brochu CA. 1999. Phylogenetics, taxonomy, and historical biogeography of Alligatoroidea. 859 Journal of Vertebrate Paleontology 19(S2):9-100.

860 Brochu CA. 2001. Crocodylian snouts in space and time: phylogenetic approaches toward 861 adaptive radiation. American Zoologist 41(3):564-585.

862 Brochu CA. 2004. Alligatorine phylogeny and the status of Allognathosuchus Mook, 1921. 863 Journal of Vertebrate Paleontology 24(4):857-873.

864

865

866

867

868

869

870

871

872

873

874

Brochu CA, Storrs W. GW. 2012. A giant crocodile from the Plio-Pleistocene of Kenya, the phylogenetic relationships of Neogene African crocodylines, and the antiquity of Crocodylus in Africa. Journal of Vertebrate Paleontology 32(3): 587-602.

Brown CM, VanBuren CS, Larson DW, Brink KS, Campione NE, Vavrek MJ, Evans DC. 2015. Tooth counts through growth in diapsid reptiles: implications for interpreting individual and size-related variation in the fossil record. Journal of Anatomy, 226(4):322-333.

Buckley LG, Currie PJ. 2014. Analysis of intraspecific and ontogenetic variation in dentition of Coelophysis bauri (Late Triassic), and implications for the systematics of isolated theropod teeth. New Mexico Museum of Natural History and Science Bulletin 63.

Busbey AB. 1995. The structural consequences of skull flattening in crocodilians. Functional Morphology in Vertebrate Paleontology 173-192. 
875 Busbey AB. 1989. Form and function of the feeding apparatus of Alligator mississippiensis. $876 \quad$ Journal of Morphology 202(1):99-127.

877 Carpenter K, Lindsey D. 1980. The dentary of Brachychampsa montana Gilmore (Alligatorinae;

878 Crocodylidae), a Late Cretaceous turtle-eating alligator. Journal of Paleontology

$879 \quad 54(6): 1213-1217$.

880

Case EC. 1925. Note on a new species of the Eocene crocodilian Allognathosuchus, A. wartheni. 881 Ann Arbor, MI: University of Michigan.

882

Cheng-kuan C. 1957. Observations on the life history of Chinese alligator (Alligator sinensis 883 Fauvel). Acta Zoologica Sinica 2(004).

884

Ciampaglio CN, Wray GA, Corliss BH. 2005. A toothy tale of evolution: convergence in tooth 885 morphology among marine Mesozoic-Cenozoic sharks, reptiles, and mammals. The 886 Sedimentary Record 3(4):1-2.

887

888

889

890

891

892

Cleuren J, Aerts P, Vree FD. 1995. Bite and joint force analysis in Caiman crocodilus. Belgian Journal of Zoology 125(1):79-94.

Cleuren J, de Vree F. 2000. Feeding in crocodilians. In Schwenk K. ed. Feeding: Form, Function, and Evolution in Tetrapod Vertebrates, Cambridge, MA: Elsiever, 359-394.

Da Silveira R, Magnusson WE. 1999. Diets of spectacled and black caiman in the Anavilhanas Archipelago, Central Amazonia, Brazil. Journal of Herpetology 33(2):181-192. 
893 D'Amore DC. 2009. A functional explanation for denticulation in theropod dinosaur teeth. The 894 Anatomical Record 292(9):1297-1314.

895

896

897

898

899

900

901

902

903

904

905

906

907

908

909

910

911

912

D'Amore DC. 2015. Illustrating ontogenetic change in the dentition of the Nile monitor lizard, Varanus niloticus: a case study in the application of geometric morphometric methods for the quantification of shape-size heterodonty. Journal of Anatomy 226(5):403-419.

D’Amore DC, McHenry C, Doody J, Clulow S, Rhind D. 2018. Claw morphometrics in monitor lizards: Variable substrate and habitat use correlate to shape diversity within a predator guild. Ecology \& Evolution https://doi.org/10.1002/ece3.4185

Daniel WJT, McHenry C. 2001. Bite force to skull stress correlation-modelling the skull of Alligator mississippiensis. In Grigg GC, Seebacher F, Franklin C. (Eds.), Crocodilian Biology And Evolution, New South Wales: Surrey Beatty and Sons, Chipping Norton, 135-143.

Davenport J, Grove DJ, Cannon J, Ellis TR, Stables R. 1990. Food capture, appetite, digestion rate and efficiency in hatchling and juvenile Crocodylus porosus. Journal of Zoology 220(4):569-592.

Delany MF. 1990. Late summer diet of juvenile American alligators. Journal of Herpetology 24(4):418-421.

Delany MF, Abercrombie CL. 1986. American alligator food habits in northcentral Florida. The Journal of Wildlife Management 50(2):348-353.

Dodson P. 1975. Functional and ecological significance of relative growth in Alligator. Journal of Zoology 175(3):315-355. 
913 Doody JS. 2009. Eyes bigger than stomach: prey caching and retrieval in the saltwater crocodile, 914 Crocodylus porosus. Herpetological Review 40(1):26.

915 Drake AG, Klingenberg CP. 2008. The pace of morphological change: historical transformation of 916 skull shape in St. Bernard dogs. Proceedings of the Royal Society B 275:71-76.

917 Drumheller SK, Brochu CA. 2014. A diagnosis of Alligator mississippiensis bite marks with 918 comparisons to existing crocodylian datasets. Ichnos 21(2):131-146.

919 Drumheller SK, Brochu CA. 2016. Phylogenetic taphonomy: a statistical and phylogenetic approach for exploring taphonomic patterns in the fossil record using crocodylians. Palaios 31(10):463-478.

Drumheller SK, Wilberg EW, Sadleir RW. 2016. The utility of captive animals in actualistic research: a geometric morphometric exploration of the tooth row of Alligator mississippiensis suggesting ecophenotypic influences and functional constraints. Journal

Edmund AG. 1962. Sequence and rate of tooth replacement in the Crocodilia. Royal Ontario Museum, Life Science Division Contributions 56: 1-42.

Edmund AG. 1969. Dentition. In: Gans C. d'A. Bellairs A, Parsons TS, eds. Biology of the Reptilia, Volume 1: Morphology A. Cambridge, MA: Academic Press, 117-200. ducks. Southeastern Naturalist 3(3), 381-390. 
932 Erickson GM, Lappin AK, Vliet KA. 2003. The ontogeny of bite-force scaling among Crocodylia. 933 Journal of Zoology 260(3):317-327.

934 Erickson GM, Lappin AK, Parker T, Vliet KA. 2004. Comparison of bite-force performance 935 between long-term captive and wild American alligators (Alligator mississippiensis). $936 \quad$ Journal of Zoology 262(1):21-28.

937 Erickson GM, Gignac PM, Steppan SJ, Lappin AK, Vliet KA, Brueggen JD, Inouye BD, Kledzik D, 938 Webb GJ. 2012. Insights into the ecology and evolutionary success of crocodilians revealed through bite-force and tooth-pressure experimentation. PLoS One 7(3):e31781.

940 Erickson GM, Gignac PM, Lappin AK, Vliet KA, Brueggen JD, Webb GJW. 2014. A comparative analysis of bite-force scaling among Crocodylia. Journal of Zoology 292(1):48-55.

942 Farlow JO, Hurlburt GR, Elsey RM, Britton AR, Langston Jr2005. Femoral dimensions and body size of Alligator mississippiensis: estimating the size of extinct mesoeucrocodylians. Journal of Vertebrate Paleontology 25(2):354-69.

Farrugia P, Polly PD, Njau JK. 2016. An analysis of shape differences in crocodylian dentition using geometric morphometrics. Journal of Vertebrate Paleontology, Program and Abstracts 133.

Ferguson MWJ. 1981. The structure and development of the palate in Alligator mississippiensis. Archives of Oral Biology 26(5):427-443.

Fish FE, Bostic SA, Nicastro AJ, Beneski JT. 2007. Death roll of the alligator: mechanics of twist feeding in water. Journal of Experimental Biology 210(16):2811-2818. 
952 Foffa D, Young MT, Stubbs TL, Dexter KG, Brusatte SL. 2018. The long-term ecology and 953 evolution of marine reptiles in a Jurassic seaway. Nature Ecology \& Evolution 2018 2(10).

954 Foote M. 1993 Contributions of individual taxa to overall morphological disparity. Paleobiology 955 19(4):403-19.

956 Frey E, Monninger S. 2010. Lost in action-the isolated crocodilian teeth from Enspel and their 957 interpretive value. Palaeobiodiversity and Palaeoenvironments 90(1):65-81.

958 Fruchard C. 2012. The Nile crocodile, a new model for investigating heterodonty and dental 959 continuous renewal in vertebrates. BioSciences Master Reviews

960 Multivariate and cladistic analyses of isolated teeth reveal sympatry of theropod dinosaurs in 961 the Late Jurassic of northern Germany. Frazzetta TH. 1988. The mechanics of cutting and 962 963 the form of shark teeth (Chondrichthyes, Elasmobranchii). Zoomorphology 108(2):93-

964

965

966

967

968

969

970

971

Fukuda Y, Saalfeld K, Lindner G, Nichols T. 2013. Estimation of total length from head length of saltwater crocodiles (Crocodylus porosus) in the Northern Territory, Australia. Journal of Herpetology 47(1):34-40.

Gabrey SW. 2010. Demographic and geographic variation in food habits of American alligators (Alligator mississippiensis) in Louisiana. Herpetological Conservation and Biology $5(2): 241-250$.

Galdikas BM, Yeager CP. 1984. Brief report: Crocodile predation on a crab-eating macaque in Borneo. American Journal of Primatology 6(1):49-51. 
972 Gerke O, Wings O. 2016.PloS One 11(7):e0158334.

973 Gignac PM, Erickson GM. 2014. Ontogenetic changes in dental form and tooth pressures

974 facilitate developmental niche shifts in American alligators. Journal of Zoology

$975 \quad 295(2): 132-142$.

976 Gignac PM, Erickson GM. 2016. Ontogenetic bite-force modeling of Alligator mississippiensis:

977 implications for dietary transitions in a large-bodied vertebrate and the evolution of $978 \quad$ crocodylian feeding. Journal of Zoology 299(4):229-38.

979 Gignac P, O’Brien H. 2016. Suchian feeding success at the interface of ontogeny and 980 macroevolution. Integrative and Comparative Biology 56(3):449-458.

981 Grigg G, Gans C. 1993. Morphology and physiology of the Crocodylia. Fauna of Australia Volume 982 2A, Amphibia and Reptilia. Canberra: Australian Government Publishing Service, 326$983 \quad 336$.

984 Groombridge B. 1982. The IUCN Amphibia-Reptilia Red Data Book, Part 1: Testudines, 985 Crocodylia, Rhynocehapalia. Gland, Switzerland: IUCN.

986 Gunz P, Mitteroecker P. 2013. Semilandmarks: a method for quantifying curves and surfaces. 987 Hystrix, the Italian Journal of Mammalogy 24(1):103-109. education and data analysis. Palaeontologia Electronica 4(1):9pp. 
990 Hanson JO, Salisbury SW, Campbell HA, Dwyer RG, Jardine TD, Franklin CE. 2014. Feeding across

991 the food web: The interaction between diet, movement and body size in estuarine

992 crocodiles (Crocodylus porosus). Austral Ecology 40(3):275-286.

993 994

995

996

997

998

999

1000

1001

1002

1003

1004

1005

1006

1007

1008

Hendrickx C, Mateus O. 2014. Abelisauridae (Dinosauria: Theropoda) from the Late Jurassic of Portugal and dentition-based phylogeny as a contribution for the identification of isolated theropod teeth. Zootaxa 3759(1):1-74.

Hendrickx C, Mateus O, Araújo R. 2015a The dentition of megalosaurid theropods. Acta Palaeontologica Polonica. A proposed terminology of theropod teeth (Dinosauria, Saurischia). Journal of Vertebrate Paleontology 35(5):e982797.

Hendrickx C, Mateus O, Araújo R. 2015b. 60(3):627-642.

Hutton JM. 1987. Growth and feeding ecology of the Nile crocodile Crocodylus niloticus at Ngezi, Zimbabwe. The Journal of Animal Ecology 56(1):25-38.

lordansky NN. 1964. The jaw muscles of the crocodiles and some relating structures of the crocodilian skull. Anatomischer Anzeiger 115:256-280.

Juarez H, D'Amore, D. 2018. Tooth morphology and function in the snake tribe Thamnophinii. Abstracts 2018 Joint Meeting of Ichthyologists and Herpetologists. Rochester. New York.

Kar SK, Bustard HR. 1983. Attacks on domestic livestock by juvenile saltwater crocodile, Crocodylus porosus, in Bhitarkanika Wildlife Sanctuary, Orissa India. Amphibia-Reptilia $4(1): 81-83$ 
1009 Kear BP, Larsson D, Lindgren J, Kundrát M. 2017. Exceptionally prolonged tooth formation in $1010 \quad$ elasmosaurid plesiosaurians. PloS One 12(2):e0172759.

1011 Kieser JA, Klapsidis C, Law L, Marion M. 1993. Heterodonty and patterns of tooth replacement 1012 in Crocodylus niloticus. Journal of Morphology 218(2): 195-201.

1013 Klingenberg CP. 2011. MorphoJ: an integrated software package for geometric morphometrics. Molecular Ecology Resources 11(2):353-357.

Langston W. 1973. The crocodilian skull in historical perspective. Biology of the Reptilia 4:263-

1016 284.

Larson DW, Brown CM, Evans DC. 2016. Dental disparity and ecological stability in bird-like dinosaurs prior to the end-Cretaceous mass extinction. Current Biology 26(10):13251333.

1020

1021

Larson DW, Currie PJ. 2013. Multivariate analyses of small theropod dinosaur teeth and implications for paleoecological turnover through time. PLoS One 8(1):e54329.

1022

1023

1024

Larsson HCE, Sidor CA. 1999. Unusual crocodyliform teeth from the Late Cretaceous

1025

Larsson HC, Sues HD. 2007. Cranial osteology and phylogenetic relationships of Hamadasuchus rebouli (Crocodyliformes: Mesoeucrocodylia) from the Cretaceous of Morocco.

1027 Zoological Journal of the Linnean Society 149(4):533-67. 
1028 LeBlanc AR, Brink KS, Cullen TM, Reisz RR. 2017. Evolutionary implications of tooth attachment 1029 versus tooth implantation: a case study using dinosaur, crocodilian, and mammal teeth. 1030 Journal of Vertebrate Paleontology 37(5):e1354006.

1031

1032

1033

1034

1035

1036

1037

1038

1039

1040

1041

1042

1043

1044

1045

Lecuona A, Pol D. 2008. Tooth morphology of Notosuchus terrestris (Notosuchia:

Mesoeucrocodylia): new evidence and implications. Comptes Rendus Palevol 7(7):407417.

Luiselli L, Akani GC, Capizzi D. 1999. Is there any interspecific competition between dwarf crocodiles (Osteolaemus tetraspis) and Nile monitors (Varanus niloticus ornatus) in the swamps of central Africa? A study from south-eastern Nigeria. Journal of Zoology 247(1):127-131.

MacLeod CD, Reidenberg JS, Weller M, Santos MB, Herman J, Goold J, Pierce GJ. 2007. Breaking symmetry: The marine environment, prey size, and the evolution of asymmetry in cetacean skulls. The Anatomical Record 290(6):539-545.

MacLeod CD, Santos MB, Lopez A, Pierce GJ. 2006. Relative prey size consumption in toothed whales: implications for prey selection and level of specialisation. Marine Ecology Progress Series 326:295-307.

Martin JE. 2007. New material of the Late Cretaceous globidontan Acynodon iberoccitanus (Crocodylia) from southern France. Journal of Vertebrate Paleontology 27(2):362-372. 
1046 McHenry CR, Clausen PD, Daniel WJ, Meers MB, Pendharkar A. 2006. Biomechanics of the

1047

1048

1049

1050

1051

1052

1053

1054

1055

1056

1057

1058

1059

1060

1061

1062

1063 rostrum in crocodilians: a comparative analysis using finite-element modeling. The Anatomical Record 288(8):827-849.

Mcllhenny EA. 1976. The Alligator's Life History. Society for the Study of Amphibians and Reptiles.

Mitteroecker P, Gunz P, Windhager S, Schaefer K. 2013. A brief review of shape, form, and allometry in geometric morphometrics, with applications to human facial mophology. Hystrix, the Italian Journal of Mammalogy 24(1):59-66.

Monfroy QT. 2017. Correlation between the size, shape and position of the teeth on the jaws and the bite force in Theropoda. Historical Biology 29(8):1089-1105.

Mook CC. 1932. A study of the osteology of Alligator prenasalis (Loomis). Bulletin of the Museum of Comparative Zoology 74(2).

Narváez I, Brochu CA, Escaso F, Pérez-García A, Ortega F. 2015. New crocodyliforms from southwestern Europe and definition of a diverse clade of European Late Cretaceous basal eusuchians. PloS One 10(11):e0140679.

Nifong JC, Silliman BR. 2013. Impacts of a large-bodied, apex predator (Alligator mississippiensis Daudin 1801) on salt marsh food webs. Journal of Experimental Marine Biology and Ecology 440:185-191. 
1064 Njau JK, Blumenschine RJ. 2006. A diagnosis of crocodile feeding traces on larger mammal

1065

1066

1067

1068

1069

1070

1071

1072

1073

1074

1075

1076

1077

1078

1079

1080

1081

1082 bone, with fossil examples from the Plio-Pleistocene Olduvai Basin, Tanzania. Journal of Human Evolution 50(2):142-162.

Norell M, Clark JM, Hutchison JH. 1994. The Late Cretaceous alligatoroid Brachychampsa montana (Crocodylia): new material and putative relationships. American Museum Novitiates 3116.

Novas FE, Pais DF, Pol D, Carvalho IDS, Scanferla A, Mones A, Riglos, MS. 2009. Bizarre notosuchian crocodyliform with associated eggs from the Upper Cretaceous of Bolivia. Journal of Vertebrate Paleontology 29(4):1316-1320.

Osborn JW. 1998. Relationship between growth and the pattern of tooth initiation in alligator embryos. Journal of Dental Research 77(9):1730-1738.

Ösi A. 2014. The evolution of jaw mechanism and dental function in heterodont crocodyliforms. Historical Biology 26(3):279-414.

Ősi A, Barrett PM. 2011. Dental wear and oral food processing in Caiman latirostris: analogue for fossil crocodylians with crushing teeth. Neues Jahrbuch für Geologie und Paläontologie-Abhandlungen 261(2):201-207.

Ősi A, Clark JM, Weishampel DB. 2007. First report on a new basal eusuchian crocodyliform with multicusped teeth from the Upper Cretaceous (Santonian) of Hungary. Neues Jahrbuch für Geologie und Paläontologie-Abhandlungen 243(2):169-177. 
1083 Pauwels OS, Barr B, Sanchez ML, Burger M. 2007. Diet records for the dwarf crocodile 1084 (Osteolaemus tetraspis tetraspis) in Rabi Oil Fields and Loango National Park, 1085 Southwestern Gabon. Hamadryad 31(2):258-264.

1086

1087

1088

1089

1090

1091

1092

1093

1094

1095

1096

1097

1098

1099

1100

Perez SI, Bernal V, Gonzalez PN. 2006. Differences between sliding semi-landmark methods in geometric morphometrics, with an application to human craniofacial and dental variation. Journal of Anatomy 208(6):769-784.

Peyer B. 1968. Comparative odontology. Chicago, IL: University of Chicago Press.

Pierce SE, Angielczyk KD, Rayfield EJ. 2008. Patterns of morphospace occupation and mechanical performance in extant crocodilian skulls: a combined geometric morphometric and finite element modeling approach. Journal of Morphology 269(7):840-864.

Pooley AC. 1989. Food and feeding habits. In Ross CA, and Garnet S. eds. Crocodiles and Alligators New York, NY: Facts on File, 76-91.

Pooley AC, Gans C. 1976. The Nile crocodile. Scientific American 234(4):114-125.

Rohlf FJ. 2010. Tps Series. Department of Ecology and Evolution, State University of New York, Stony Brook.

Rohlf FJ. 2013. TpsRelw 1.53. Dept. of Ecology and Evolution, State Univ. of New York at Stony Brook, Stony Brook. 
1101 Rootes WL, Chabreck RH. 1993. Cannibalism in the American alligator. Herpetologica 49(1):99-

1102

1103

1104

1105

1106

1107

1108 107.

Rommel S. 1990. Osteology of the bottlenose dolphin. In Leatherwood S, Reeves RR. Eds, The Bottlenose Dolphin, Cambridge, MA: Elsevier, 29-49.

Ross CA, Magnusson WE. 1989. Living crocodilians. In Ross CA, and Garneteds. Crocodiles and Alligators New York, NY: Facts on File, 58-73.

Sadleir RW, Makovicky PJ. 2008. Cranial shape and correlated characters in crocodilian evolution. Journal of Evolutionary Biology 21(6):1578-1596.

Salas-Gismondi R, Flynn JJ, Baby P, Tejada-Lara JV, Wesselingh FP, Antoine, PO. 2015. A Miocene hyperdiverse crocodylian community reveals peculiar trophic dynamics in proto-Amazonian mega-wetlands. Proceedings of the Royal Society of London B: Biological Sciences 282(1804):20142490.

Salas-Gismondi R, Flynn JJ. Baby P, Tejada-Lara JV, Claude J, Antoine PO. 2016. A new 13 million year old gavialoid crocodylian from proto-Amazonian mega-wetlands reveals parallel evolutionary trends in skull shape linked to longirostry. PloS One 11(4):e0152453.

Sampaio PRM, da Silva MN, de Matos SA, de Matos LRA, Acosta M. 2013. First report of predation by a caiman (Paleosuchus trigonatus, Crocodylia: Alligatoridae) on a caecilian (Caecilia marcusi, Gymnophiona: Caecilidae). Salamandra 49(4):227-228. 
1119 Santos SA, Nogueira MS, Pinheiro MS, Campos Z, Magnusson WE, Mourao GM. 1996. Diets of 1120 Caiman crocodilus yacare from different habitats in the Brazilian pantanal. Herpetological Journal 6:111-117.

Sassoon J, Foffa D, Marek R. 2015. Dental ontogeny and replacement in Pliosauridae. Royal Society Open Science 2(11):150384.

Selvaraj G. 2012. Herpetological notes: Tomistoma schlegelii (False Gharial). Diet. Herpetological Review, 43:608-609.

Schwarz-Wings D, Rees J, Lindgren J. 2009. Lower cretaceous mesoeucrocodylians from Scandinavia (Denmark and Sweden). Cretaceous Research 30(5):1345-1355.

Sheets HD. 2012. IMP software series. Computer software and manual. Buffalo, NY: Canisius College.

Sheets HD, Kim K, Mitchell CE. 2004. A combined landmark and outline-based approach to ontogenetic shape change in the Ordovician trilobite Triarthrus becki. In Morphometrics

Sheets HD, Zelditch ML. 2013. Studying ontogenetic trajectories using resampling methods and landmark data. Hystrix, the Italian Journal of Mammalogy 24(1):67-73.

Shimada, K. 2001. On the concept of heterodonty. Journal of Fossil Research 34(2):52-54. Journal of Morphology 251(1):38-72. 
1138 Shimada K. 2004. The relationship between the tooth size and total body length in the sandtiger

1139

1140

1141

1142

1143

1144

1145

1146

1147

1148

1149

1150

1151

1152

1153

1154

1155

1156

1157 shark, Carcharias taurus (Lamniformes: Odontaspididae). Journal of Fossil Research $37: 76-81$.

Shimada K, Seigel JA. 2005. The relationship between the tooth size and total body length in the goblin shark, Mitsukurina owstoni (Lamniformes: Mitsukurinidae). Journal of Fossil Research 38:49-56.

Shoop CR, Ruckdeschel CA. 1990. Alligators as predators on terrestrial mammals. American Midland Naturalist 124(2):407-412.

Smith JB, Dodson P. 2003. A proposal for a standard terminology of anatomical notation and orientation in fossil vertebrate dentitions. Journal of Vertebrate Paleontology 23(1):112.

Smith JB, Vann DR, Dodson P. 2005. Dental morphology and variation in theropod dinosaurs: implications for the taxonomic identification of isolated teeth. The Anatomical Record 285(2):699-736.

Subalusky AL, Fitzgerald LA, Smith LL. 2009. Ontogenetic niche shifts in the American Alligator establish functional connectivity between aquatic systems. Biological Conservation 142(7):1507-1514.

Tavares SAS, Branco FR, de Souza Carvalho I, Maldanis L. 2017. The morphofunctional design of Montealtosuchus arrudacamposi (Crocodyliformes, Upper Cretaceous) of the Bauru Basin, Brazil. Cretaceous Research 79:64-76. 
1158 Taylor JA. 1979. The foods and feeding habits of subadult Crocodylus porosus Schneider in 1159 northern Australia. Wildlife Research 6(3):347-359.

1160 Thorbjarnarson JB. 1990. Notes on the feeding behavior of the gharial (Gavialis gangeticus) 1161 under semi-natural conditions. Journal of Herpetology 24(1):99-100.

1162 Tinius A, Russell AP. 2017. Points on the curve: An analysis of methods for assessing the shape 1163 of vertebrate claws. Journal of Morphology 278(2):150-69.

1164 Torices A, Reichel M, Currie PJ. 2014. Multivariate analysis of isolated tyrannosaurid teeth from 1165 the Danek Bonebed, Horseshoe Canyon Formation, Alberta, Canada. Canadian Journal $1166 \quad$ of Earth Sciences 51(11):1045-1051.

1167 1168

Valkenburgh BV, Ruff CB. 1987. Canine tooth strength and killing behaviour in large carnivores. Journal of Zoology 212(3):379-397.

Verdade LM. 2000. Regression equations between body and head measurements in the broadsnouted caiman (Caiman latirostris). Revista Brasileira de Biologia 60(3):469-482.

Vullo R, Allain R, Cavin L. 2016. Convergent evolution of jaws between spinosaurid dinosaurs and pike conger eels. Acta Palaeontologica Polonica 61(4):825-828.

Wallace KM, Leslie AJ. 2008. Diet of the Nile crocodile (Crocodylus niloticus) in the Okavango Delta, Botswana. Journal of Herpetology 42(2):361-368. 
1175 Walmsley CW, Smits PD, Quayle MR, McCurry MR, Richards HS, Oldfield CC, ... \& McHenry CR.

1176

1177

1178

1179

1180

1181

1182

1183

1184

1185

1186

1187

1188

1189

1190

1191

1192

1193

2013. Why the long face? The mechanics of mandibular symphysis proportions in crocodiles. PLoS One 8(1):e53873.

Watanabe A, Slice DE. 2014. The utility of cranial ontogeny for phylogenetic inference: a case study in crocodylians using geometric morphometrics. Journal of Evolutionary Biology 27(6):1078-1092.

Webb GJW, Manolis SC, Buckworth R. 1982. Crocodylus johnstoni in the McKinlay river area, NTI Variation in the diet, and a new method of assessing the relative importance of prey. Australian Journal of Zoology 30(6):877-899.

Webb GJW, Messel H. 1978. Movement and dispersal patterns of Crocodylus porosus in some rivers of Arnhem Land, Northern Australia. Wildlife Research 5(2):263-283.

Westergaard B, Ferguson MWJ. 1986. Development of the dentition in Alligator mississippiensis. Early embryonic development in the lower jaw. Journal of Zoology 210(4):575-597.

Westergaard B, Ferguson MWJ. 1987. Development of the dentition in Alligator mississippiensis. Later development in the lower jaws of embryos, hatchlings and young juveniles. Journal of Zoology 212(2):191-222.

Westergaard B, Ferguson MWJ. 1990. Development of the dentition in Alligator mississippiensis: upper jaw dental and craniofacial development in embryos, hatchlings, 
1194 1195

and young juveniles, with a comparison to lower jaw development. American Journal of Anatomy 187(4):393-421.

Wilberg EW. 2017. Investigating patterns of crocodyliform cranial disparity through the Mesozoic and Cenozoic. Zoological Journal of the Linnean Society 181(1):189-208.

Wu XB, Xue H, Wu LS, Zhu JL, Wang RP. 2006. Regression analysis between body and head measurements of Chinese alligators (Alligator sinensis) in the captive population. Animal Biodiversity and Conservation 29(1):65-71.

Young MT, Brusatte SL, Beatty BL, De Andrade MB, Desojo JB. 2012. Tooth-on-tooth interlocking occlusion suggests macrophagy in the Mesozoic marine crocodylomorph Dakosaurus. The Anatomical Record 295(7):1147-1158.

Zahradnicek O, Buchtova M, Dosedelova H, Tucker AS. 2014. The development of complex tooth shape in reptiles. Frontiers in Physiology 5:74.

Zelditch ML, Sheets HD, Fink WL. 2003. The ontogenetic dynamics of shape disparity. Paleobiology 29(1):139-156.

Zelditch M, Swiderski D, Sheets DH, Fink W. 2004. Geometric Morphometrics for Biologists: A Primer. Waltham, MA: Elsevier Academic Press. 
FIGURE LEGENDS

1211 Figure 1: Data collection methods. A) We numbered teeth based on position and host bone 1212 (only the left teeth are labeled). Teeth P4, M5, and M10 are defined as the enlarged teeth in

1213 this specimen. B) We photographed each tooth individually, and traced the margins. The

1214 software converted each outline into 30 equidistant coordinates. Three coordinates were

1215 transformed into landmarks (magenta) and the rest into semilandmarks (green). C) For skulls,

1216 we produced an outline from the dorsal perspective, with 50 coordinates on each margin that

1217 were transformed into landmarks (magenta) and semilandmarks (green). (Specimen depicted:

1218 Crocodylus palustris AMNH 96134.) [Half page width]

1219 Figure 2: Variability within the first principal component for teeth. A) Vector diagrams indicate

1220 the maximum range of variance (vectors) from the mean (points) for both cranial and dentary

1221 teeth. Landmarks are in magenta and semilandmarks are in green. B) Scores from the first and

1222 second principal components are plotted in a morphospace, with major taxonomic groupings

1223 labeled. [Full page width]

1224 Figure 3: Partial Least Squared (PLS) two-block analysis of shape. A) Vector diagrams indicate

1225 shape variance of PLS1 for skull shape (Block 1) and average tooth shape (Block 2). B) PLS1

1226 scores for both blocks were regressed, with colors and shapes representing species. Regression

1227 information is listed. [Full page width]

1228 Figure 4: Heterodonty represented by Foote's morphological disparity. Ln scaling of

1229 Morphological Disparity (MD) for size (A) and shape (B) are plotted against the In of skull length.

1230 Colors and shapes represent species, and regression information is listed. [Half page width] 
1231 Figure 5: Heterodonty by tooth position. Centroid Size (CS) and principal component one (PC1)

1232 for extant Alligatoroidea (A,D), Crocodyloidea (B,E), and remaining taxa (C,F), plotted against

1233 position along the arcade. Colors represent major taxonomic groups. See Figure 2 for a visual

1234 representation of shape change depicted by PC1 scores. [Full page width]

1235 Figure 6: Regression information for shape heterodonty. Slope $(m)$ and y-intercept $(b)$ data for

1236 regressions of the first principal component plotted against tooth position for individuals. Error

1237 bars indicate $95 \%$ confidence intervals, and colors and shapes represent species. Regression

1238 statistics are available in Table S2. [Full page width]

1239 Figure 7: Direct comparisons between selected extant and extinct taxa. The size axis

1240 represents normalized centroid size (ranging from 0.00 to 0.20 ), and the shape axis represents

1241 scores from the first principal component (ranging from -0.04 to 0.04). Taxa are grouped by A)

1242 modern specimens with high molariform distal teeth, B) modern specimens that display high

1243 size heterodonty, C) slender-snouted specimens, D) Hamadasuchus rebouli, E) Borealosuchus

1244 sternbergii and Leidyosuchus canadensis, and F) fossil globidont specimens. (Note:

1245 Borealosuchus sternbergii teeth were not size normalized by its own skull length, as indicated

1246 by hollow bars.) Scale $=$ five $\mathrm{cm}$. [Full page width] 


\section{Figure 1}

Data collection methods

A) We numbered teeth based on position and host bone (only the left teeth are labeled).

Teeth P4, M5, and M10 are defined as the enlarged teeth in this specimen. B) We photographed each tooth individually, and traced the margins. The software converted each outline into 30 equidistant coordinates. Three coordinates were transformed into landmarks (magenta) and the rest into semilandmarks (green). C) For skulls, we produced an outline from the dorsal perspective, with 50 coordinates on each margin that were transformed into landmarks (magenta) and semilandmarks (green). (Specimen depicted: Crocodylus palustris AMNH 96134.) [Half page width]

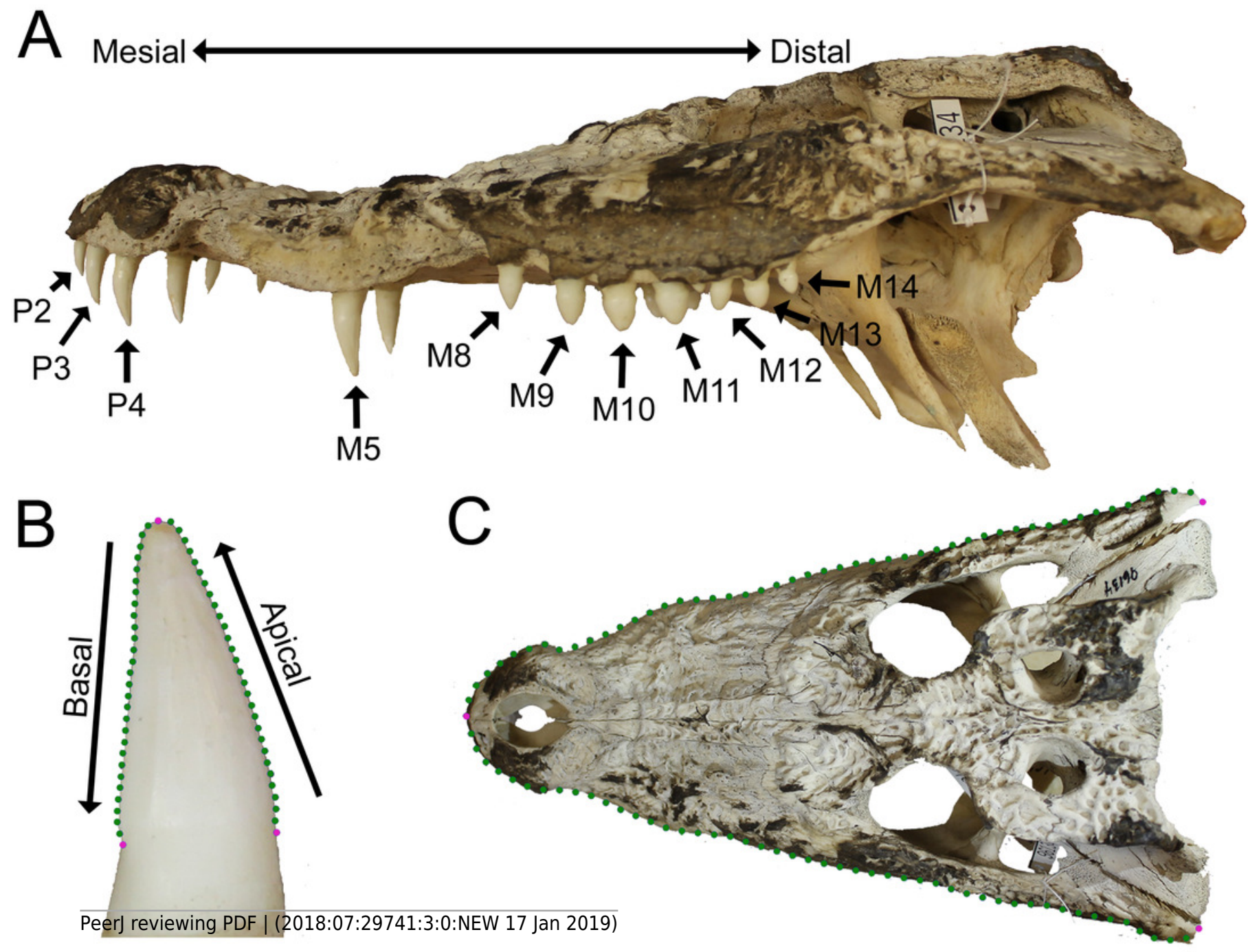


Figure 2

Variability within the first principal component for teeth.

A) Vector diagrams indicate the maximum range of variance (vectors) from the mean (points) for both cranial and dentary teeth. Landmarks are in magenta and semilandmarks are in green. B) Scores from the first and second principal components are plotted in a morphospace, with major taxonomic groupings labeled. [Full page width]

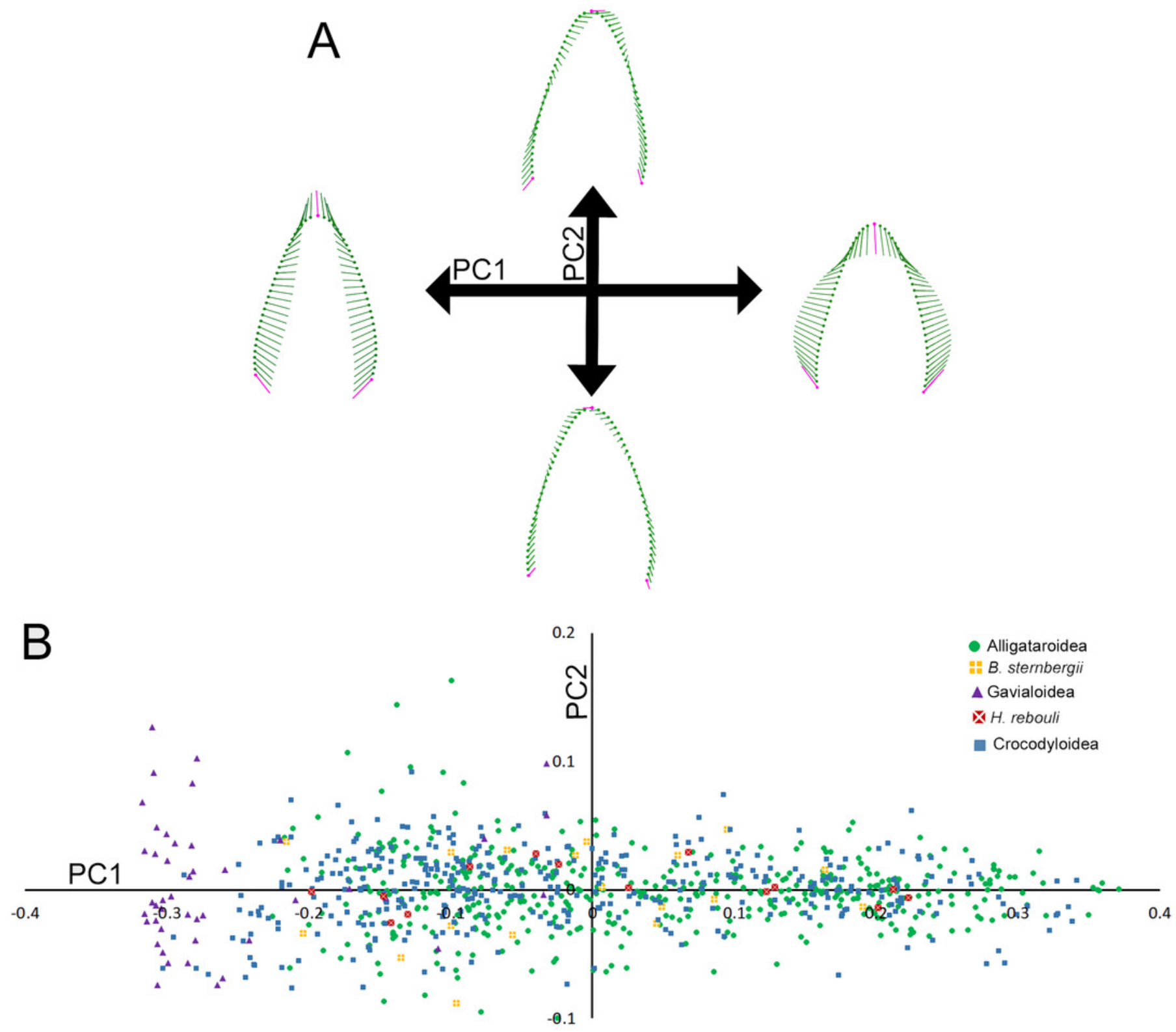


Figure 3

Partial Least Squared (PLS) two-block analysis of shape

A) Vector diagrams indicate shape variance of PLS1 for skull shape (Block 1) and average tooth shape (Block 2). B) PLS1 scores for both blocks were regressed, with colors and shapes representing species. Regression information is listed. [Full page width]

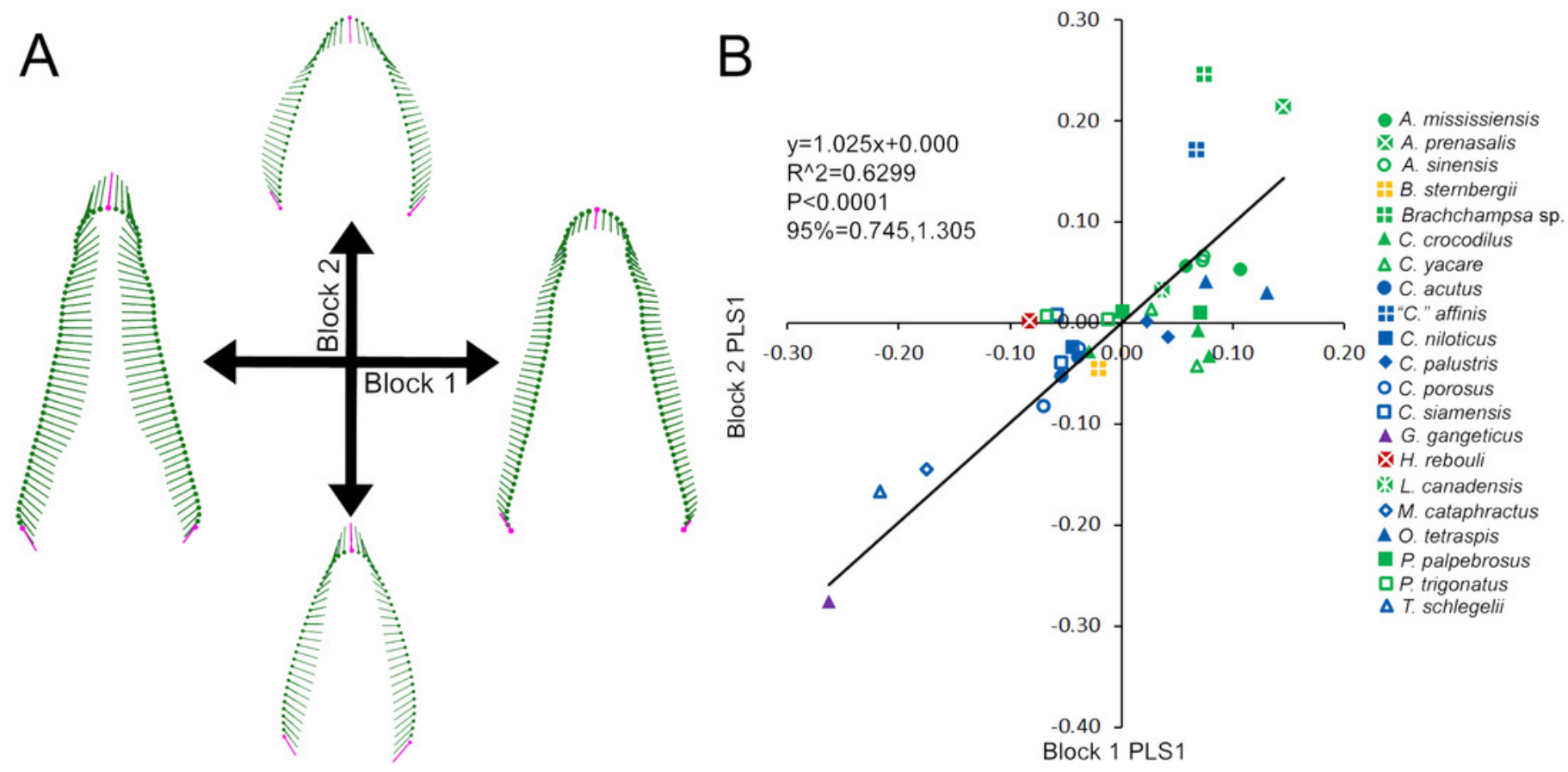




\section{Figure 4}

Heterodonty represented by Foote's morphological disparity

Ln scaling of Morphological Disparity (MD) for size (A) and shape (B) are plotted against the In of skull length. Colors and shapes represent species, and regression information is listed. [Half page width] 

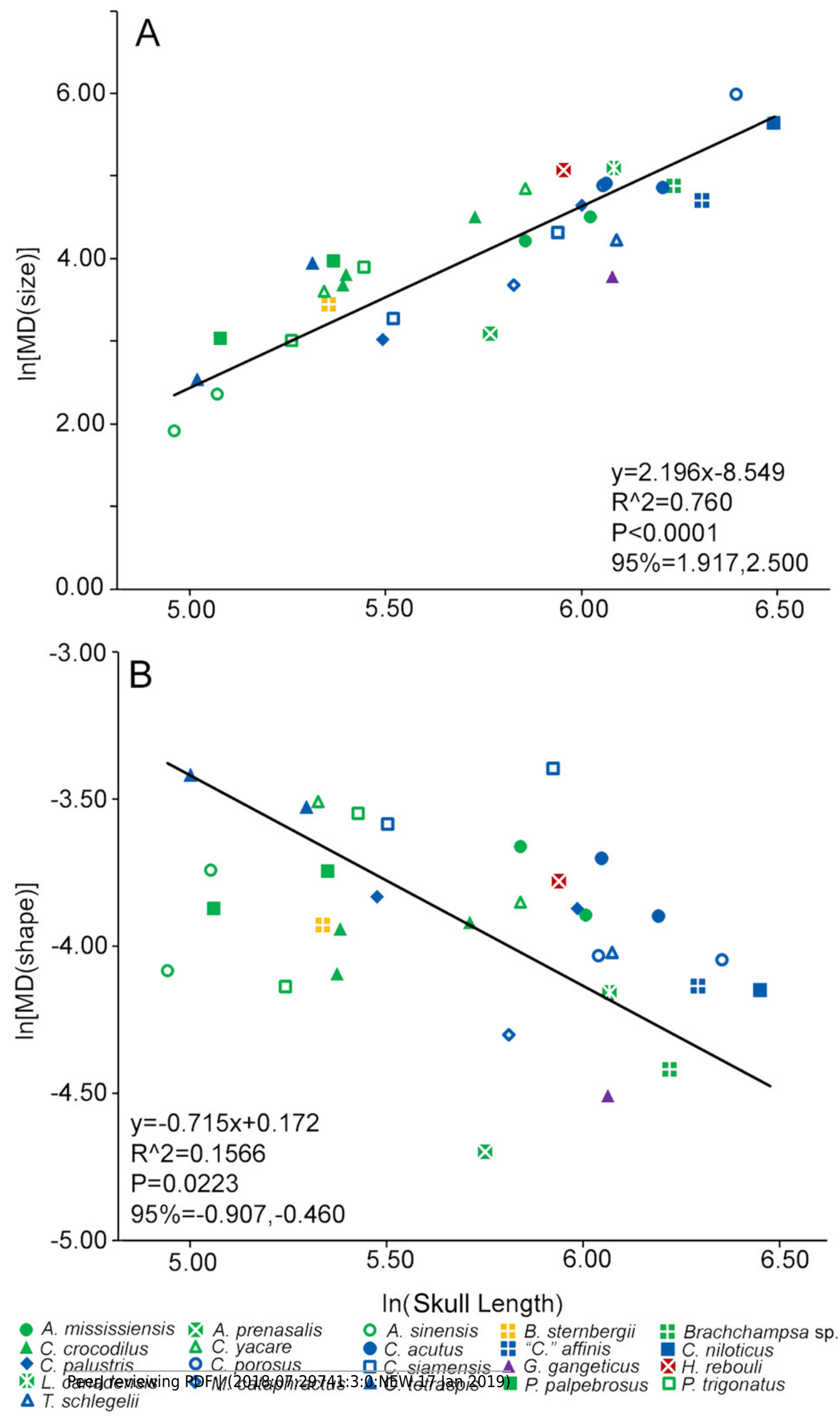
Figure 5

Heterodonty by tooth position

Centroid Size (CS) and principal component one (PC1) for extant Alligatoroidea (A,D), Crocodyloidea $(\mathrm{B}, \mathrm{E})$, and remaining taxa $(\mathrm{C}, \mathrm{F})$, plotted against position along the arcade. Colors represent major taxonomic groups. See Figure 2 for a visual representation of shape change depicted by PC1 scores. [Full page width]
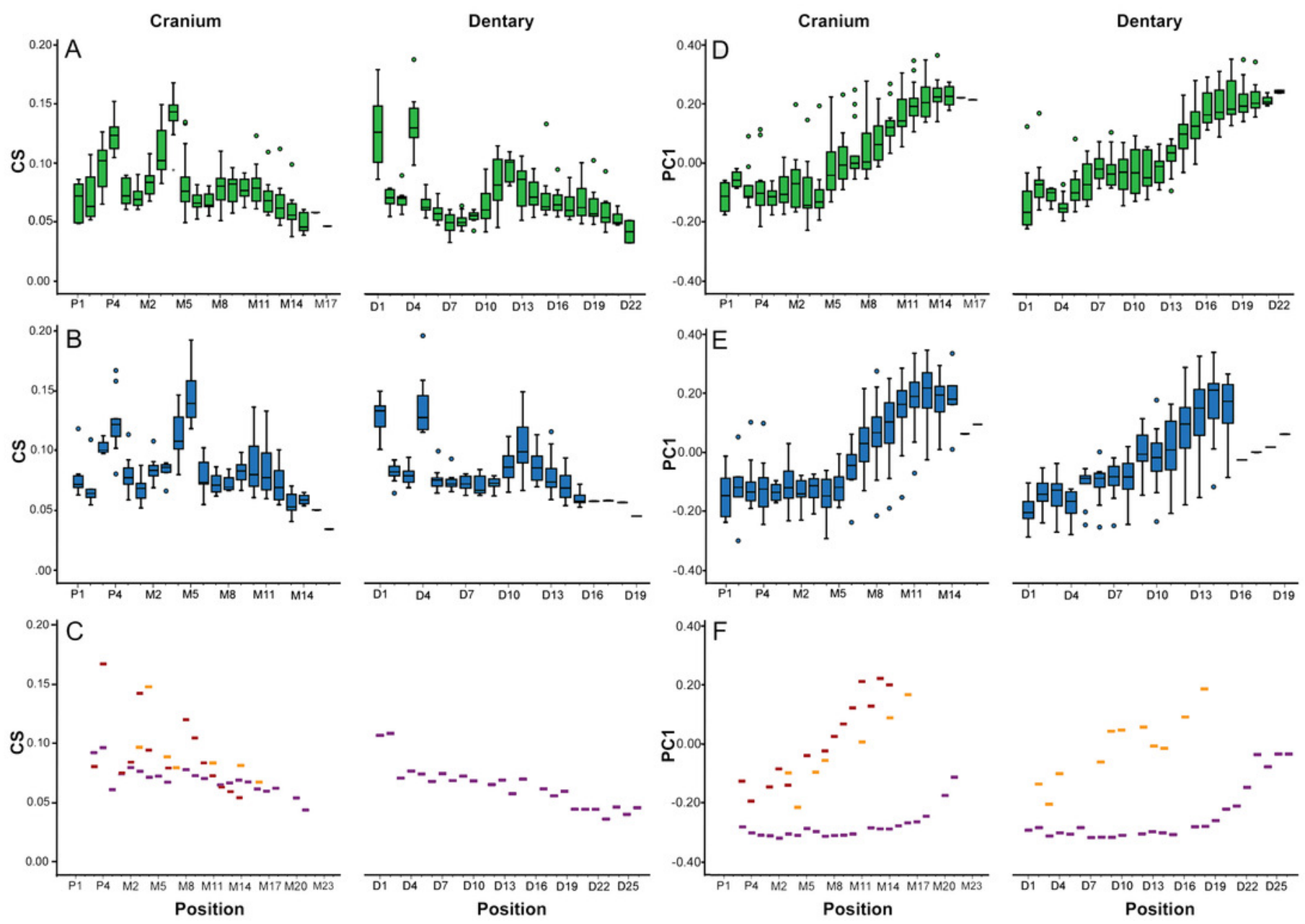


\section{Figure 6}

Regression information for shape heterodonty

Slope $(m)$ and $y$-intercept $(b)$ data for regressions of the first principal component plotted against tooth position for individuals. Error bars indicate $95 \%$ confidence intervals, and colors and shapes represent species. Regression statistics are available in Table S2. [Full page width]

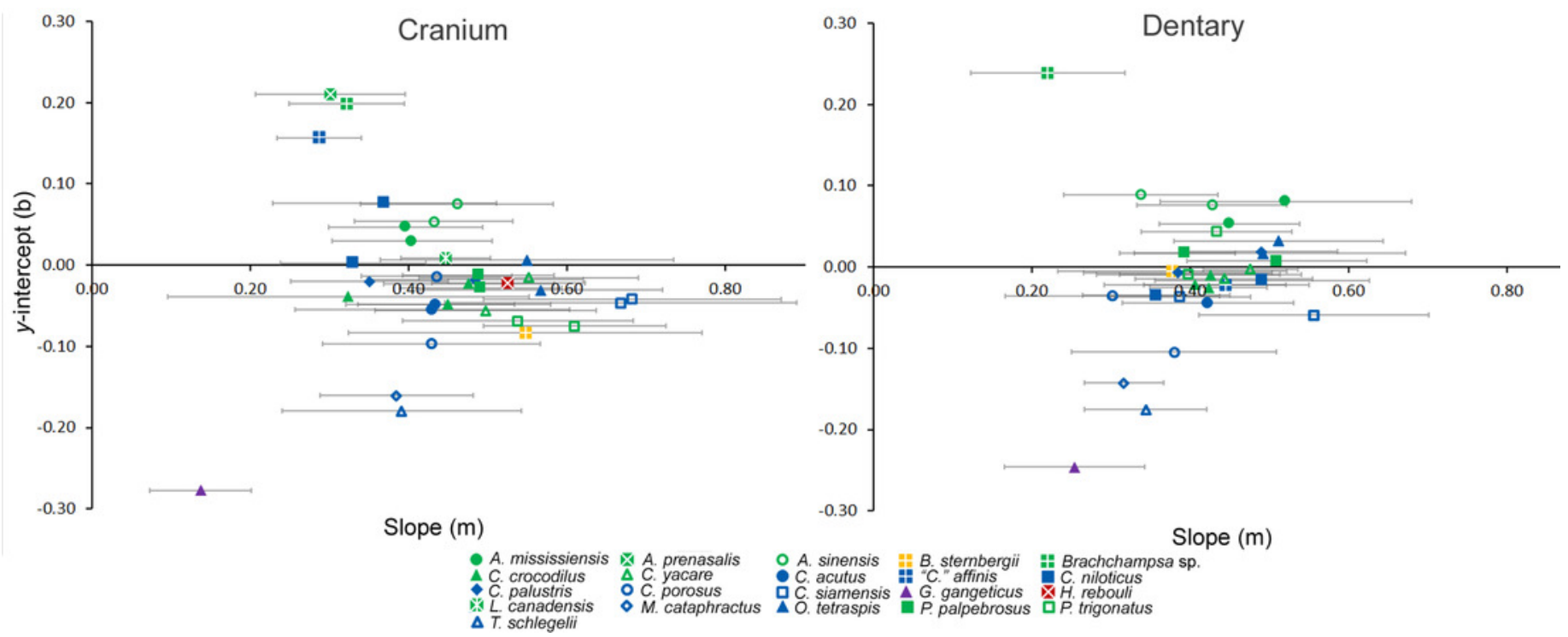




\section{Figure 7}

Direct comparisons between selected extant and extinct taxa

The size axis represents normalized centroid size (ranging from 0.00 to 0.20 ), and the shape axis represents scores from the first principal component (ranging from -0.04 to 0.04 ). Taxa are grouped by $\mathrm{A}$ ) modern specimens with high molariform distal teeth, B) modern specimens that display high size heterodonty, C) slender-snouted specimens, D) Hamadasuchus rebouli, E) Borealosuchus sternbergii and Leidyosuchus canadensis, and F) fossil globidont specimens. (Note: Borealosuchus sternbergii teeth were not size normalized by its own skull length, as indicated by hollow bars.) Scale = five $\mathrm{cm}$. [Full page width] 


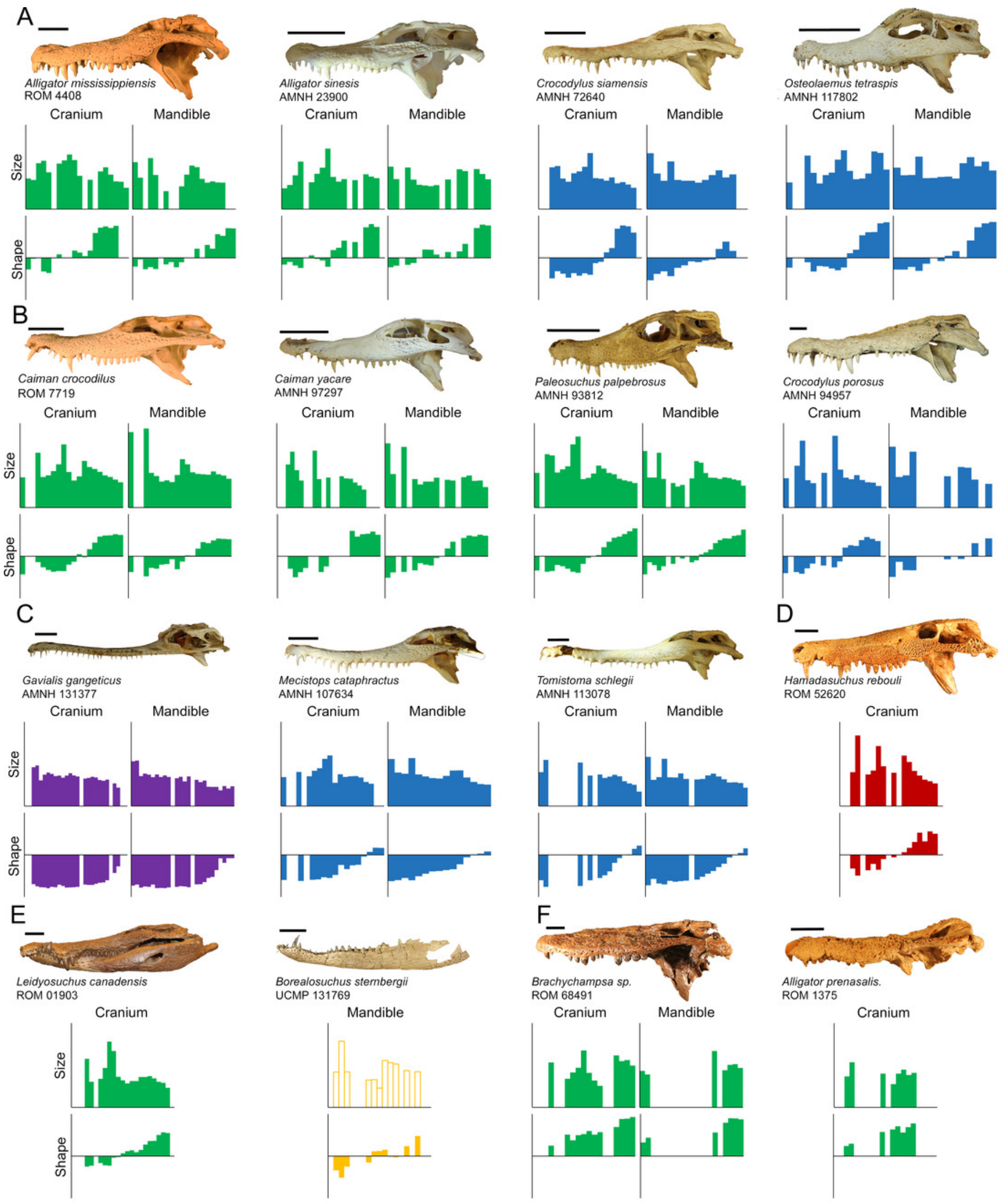

